\title{
3. Sexuality, Migration, Space
}

Migration refers to the movement of people through space. People exchange one context of their everyday lives with another, sometimes going through a chain of places, sometimes moving in circles. They not only take with them notions about the place(s) they have left behind but also bring along imaginations about the place they are going to, shaped by the media or reports by other travelers. But the places they arrive at (or return to) will not likely be what they have imagined. Thus, for migrants, a process of decoding begins. Based on their previous experiences, they try to make sense of the social rules governing the new place and attempt to create a meaningful space for themselves within it. In this process, their perceptions of themselves and of the new place begins to shift, just as their perception of the place(s) they have come from begins to change, too. This is not a one-way process, with 'locals' coding and 'migrants' decoding. Upon closer inspection, many 'locals' turn out to have a migration background of sorts, be it that they have immigrant spouses or grandparents. Moreover, the presence of migrant people in the new place in itself produces effects. Their perception of the new place not only shapes the ways they experience their new social environment but also the way they act within it. These material practices in turn both confirm and subvert the hegemonic social inscriptions of these places.

These social constructions of space are highly stratified. That is, they work along the lines of categories that structure the social such as gender, race, ethnicity, or sexuality. In other words: Identities and space constitute each other. Sexual identity, for example, shapes people's perceptions and experiences of a place and their practices within that place, be it a lesbian bar, the workplace, or the family home. These perceptions and practices and their representations produce collective spatial imaginaries, such as the myth of the urban gay community or the notion of the paradigmatic heterosexual nuclear family home. Such collective imaginations are always manifested materially as well, be it in the form of brick and mortar, ${ }^{1}$ in moving bodies, in social networks, or in flows of goods and capital. At the same time, precisely because they are organized around defined social positions, such imagined geographies also generate exclusions of certain with "Parents," "Child 1," "Child 2," expressing and reproducing the nuclear family norm. 
people, who can be physically excluded from particular places, rendered invisible within them, or seen as not belonging.

With its focus on queer migrant women in Switzerland, this study is concerned with people who inhabit an intersectional social position for which hardly any designated spaces exist. Yet queer migrant women are corporeally present, incorporating this allegedly 'impossible' subject position, meaning that in most places, not all aspects of queer migrant women's Selves are visible or acknowledged. This discrepancy raises the question of how queer migrant women negotiate the dominant meanings inscribed in their everyday (and not-so-everyday) spaces, and how their perceptions of these spaces and their practices in them reproduce or disrupt their hegemonic inscriptions.

In order to address these questions, this study integrates approaches from two bodies of scholarship that approach these issues from different perspectives: queer migration scholarship and geographies of sexualities (or queer geographies - I use these terms interchangeably). The chapter is organized as follows: First, Chapter 3.1 outlines the understanding of space that has both guided the conceptualization of this research and re-emerged through it. Second, while the two bodies of literature of queer migration scholarship and geographies of sexualities have recently begun to intersect, they have each developed their own genealogies, foci, and concerns. Hence Chapters 3.2 and 3.3 introduce these two fields of research separately, notably identifying the research gaps within them that this study addresses. Chapter 3.4 introduces foundational concepts that have emerged from thinking sexuality, migration, and space together, focusing on the contributions this study draws on and extends. Finally, Chapter 3.5 raises the question of who 'queer migrant women' are and how they are addressed within this study.

\subsection{Embodied Geographies}

"Is it really not possible to kiss spaces?" ("Kann man Räume wirklich nicht küssen?") Peter Weichhart asks in the title of his provocative essay about rivaling concepts of space in geography (Weichhart 1998). Weichhart argues that the most basic question in geography, "What is space?" is not answerable as such, but it can be injected with potential if reformulated as: "What specific meaning of the word 'space' is used by whom and to what end?” (ibid:3, emphasis original, my translation). This sub-chapter engages with these questions, aiming to embed this research within two theorizations of the spatial - one by Doreen Massey and another by Sallie A. Marston, John Paul Jones III, and Keith Woodward. Both have guided the conceptualization of this study and the analyses it offers.

This study is an embodied geography. It is about the ways in which we (re)make ourselves and our environment in our everyday (and not-so-everyday) lives by what we say, wear, eat, touch, desire, build; by where we choose to go or stay away from; by whose company we seek or avoid; by what fascinates or repulses us; and by what we feel is the right or logical thing to do. It is equally a geography of exclusions. It is about the ways our very choices and actions are restricted, our access to places barred depending on who we are perceived to be, and about how not only our thinking but also our innermost 
desires, feelings, emotions, and affects are channeled and disciplined by discourses of globalization, capitalism, nation, human rights, and others.

This is also an embodied geography because it refuses to treat these discourses as amorphous, ubiquitous conglomerates that 'somehow', on the 'large scale,' determine the world and how it works, as many theories would have it. It is a geography that fundamentally rejects grand theories of a structured and organized space which can be fully known and understood, but instead frames the workings of the world as a flurry of mundane deliberate and non-intentional actions that constantly assemble and disassemble bodies and things. Such a geography conceives of discourses as necessarily embodied and repetitive social practices - mostly everyday, ordinary practices, but often also not-so-everyday practices - without which hegemonies would cease to exist. It is in banal acts that discourses are perpetuated but also fail to be perpetuated, and that is what interests me here: how everyday and not-so-everyday social practices, as well as the bodies, objects, and landscapes they produce, are shaped but never entirely determined by hegemonic discourses, and how these resistances, failures, and slippages drive social change. In other words, this is a geography about how the perpetuation of hegemonic discourses depends on their repeated and necessarily embodied performance, which is always necessarily flawed, different, changing, and ultimately unpredictable. In focusing on the material movement of bodies and objects across space, this study is also about the stickiness and materiality of space, which speaks against simplistic ideas about placelessness, mobility, and flows that often pervade writings about migration and globalization.

This sub-chapter introduces some of the geographical thinking that enables such a conceptualization of space, and which has inspired my attempt to consider the migration biographies and everyday spaces and practices of queer migrant women in Switzerland beyond simplistic binary models of structure and agency. A purely structural view would necessarily highlight absence and exclusion. At the same time, framing queer migrant women as gloriously unruly protagonists in a queer theory would mean to ignore the discursive frameworks queer migrants are forced to navigate in the Swiss context. Therefore, a theory is needed that can address both the fact that there are no designated spaces for queer migrant women in Switzerland and the fact that these subjects' corporeal presence and practices are always accommodating, embracing, refusing, adopting, and upsetting what is 'normal' in Switzerland. An embodied geography with a focus on the (re)production of space through repetitive re-enactments of social relations seems to enable just that.

\subsubsection{Doreen Massey's Three Propositions about Space}

Some geographers have begun to question the spatialities that have been brought to 'globalization' by globalization theorists. These authors have particularly criticized the conceptual separation of the 'global' and the 'local' which pervades academic literature about globalization, framing the concepts in terms of a binary that privileges an all-encompassing, powerful, abstract 'global' over a specific, material, powerless 'local.' Taking issue with the implications such views have for conceptualizations of the formation of subjectivity, space, and place, these authors have instead suggested framing 'globaliza- 
tion' as a flurry of embedded, embodied, and often very banal interactions (Amin 2002, Gibson-Graham 2002, Marston et al. 2005, Marston et al. 2007, Massey 1994 and 2005).

Doreen Massey suggests we think of space as "simultaneity of stories-so-far" (Massey 2005:9, see also Massey 1998 and 2004). She writes against what she sees as three common failures in the imagination of space, each of which has been serving specific political ends. The first common failure is to imagine space as a surface to cross or a territory to conquer - a notion that has led people in the West to think of other places and societies as being defined social entities fixed 'on' that surface, passively awaiting the arrival of their active counterparts - the colonizer, or global capital, for instance. Second, Massey writes against the narrative of the alleged inevitability of (a very specific neoliberal, technology-driven) globalization. Third, she takes issue with the common division between space as the abstract, the general, the global, and place as the specific, the local (Massey 2005:4-5).

Massey formulates her tentative alternative approach to space in the form of three propositions about space: ${ }^{2}$

First, that we recognize space as the product of interrelations; as constituted through interactions, from the immensity of the global to the intimately tiny.

Second, that we understand space as the sphere of the possibility of the existence of multiplicity in the sense of contemporaneous plurality; as the sphere in which distinct trajectories coexist; as the sphere therefore of coexisting heterogeneity. Without space, no multiplicity; without multiplicity, no space.

Third, that we recognize space as always under construction. Precisely because space [...] is a product of relations-between, relations which are necessarily embedded material practices which have to be carried out, it is always in the process of being made. It is never finished; never closed. (Massey 2005:9, emphasis added)

Massey's project is decidedly political. She argues that "thinking the spatial in a particular way can shake up the manner in which certain political questions are formulated" (ibid:9). She demonstrates this by linking her three propositions about space with three recent shifts towards what she calls a "progressive politics":

The first proposition - that space is a product of interrelations - Massey sees as resonating with the emergence of an anti-essentialist politics, which replaces an individualistic-liberalist identity politics conceiving of identities as always already formed with a politics that exposes the very process of constituting and naturalizing identities as a crucial stake of the political. Such a politics "lays its stress upon the relational constructedness of things" and is "wary therefore about claims to authenticity based in notions of unchanging identity." In other words, just as identities are always multiple and in the process of becoming, so is space, which does not preexist identities or the relations between them (ibid:10).

Massey aligns her second proposition - to think of space as the sphere of coexistence - with the emphasis certain progressive political discourses place on difference and

2 Massey insists that her propositions are not about finally having found the truth about space but rather seek to "stress just how genuinely difficult it is not to resort to an a priori politics of topographies" (Massey 2005:172). 
heterogeneity. She particularly refers to theorists' and activists' insistence that the story of the world cannot be told as the story of the West alone (or as the story of its dominant figure, the white heterosexual male), but that this story has to be framed as one particular story among many other - coexisting - stories. Massey's insistence on coexistence and multiplicity may seem banal and self-evident, but the concepts have far-reaching consequences. For instance, this proposition precludes the notion of a "pre-contact society" inherent to colonialist narratives. Such conceptualizations of place represent an "essentialist, billiard-ball view" of place in which first a difference between bounded places is established, and then these already-different places come into contact with each other. By contrast, Massey argues that societies have always been in contact with each other, exactly because place is necessarily always a meeting point of different trajectories. Hence the specificity of place is always derived from relations with the beyond, and these relations may span the globe (ibid:66ff.).

In this context Massey also addresses the ubiquitous dichotomy established between space and place. Place, she says, has come to signify the "geographical source of meaning," 'home,' the local, the everyday, the bounded, the coherent, the authentic, the traditional, and the grounded - the latter a term with which many geographers are particularly enamored since it is exactly in this 'groundedness' that many see geography as differing from other, more 'abstract' or 'large-scale' social sciences. This 'place' is pitted against either the 'global' - associated with power, alienation, and instant connectivity - or 'space' - of which Massey asks: "As what? the outside? the abstract? the meaningless?" (ibid:6, emphasis original). She asks provocatively: "Where would you draw the line around the lived reality of your daily life? In such approaches words such as 'real,' 'everyday,' 'lived, ' 'grounded' are constantly deployed and bound together; [...] they counterpose themselves to a wider 'space' which must be abstract, ungrounded, universal, even threatening. [...] If we really think space relationally, then it is the sum of all our connections, and in that sense utterly grounded, and those connections may go round the world" (ibid:184-185).

Additionally, the failure to think of space as the sphere of coexistence not only frames places as already-divided-up and bounded but also organizes space along one temporal sequence, with coexisting places paradoxically being interpreted as different stages on a single timeline. In this ubiquitous narrative, the U.S. figures as the spearhead of modernism and progress, with all other places lagging more or less 'behind.' In such a rendering, "Africa' is not different from Western Europe, it is (just) behind" (ibid:68, emphasis original). Such discourses of 'backwardness' are entangled with discourses of development, which continue to be organized around the assumption of unidirectional flows of knowledge, capital, and values (such as what, for instance, represents a 'proper' gay identity) from the 'developed' to the 'developing' world. This formulation denies certain regions of the world their own particular trajectories, histories, temporalities, and, especially, their own presents and futures. In these renderings, as Massey says, "the future is already foretold," which contradicts her third proposition: to think of space as always in the process of emerging (ibid:68, see also Fabian 1983).

Massey aligns her third proposition to think of space as always under construction with "an increasingly vocal insistence within political discourses on the genuine openness of the future." This openness acts against the determinism pervading grand nar- 
ratives of Progress, Development and Modernization (ibid:11, emphasis added). Here, Massey draws on Ernesto Laclau and Chantal Mouffe's notion of radical democracy, Gilles Deleuze and Felix Guattari's notion of active experimentation, as well as on the work of queer theorist William Haver to illustrate this emerging politics of a radically open future. "In this open interactional space there are always connections yet to be made, juxtapositions yet to flower into interaction (or not, for not all potential connections are established), relations which may or may not be accomplished" - it is also a space of "loose ends and missing links" (ibid:11-12).

Extending this argument, Massey insists that space has an intrinsic element of unpredictability, which she calls "the chance of space." She uses the figure of the accidental neighbor to exemplify this element of chance, only to warn us immediately of simplistic dichotomies about what may represent order (e.g. 'the state'), and chaos respectively (e.g. 'the street market') (ibid:111-112). She also cautions against valuing either openness or closure as 'good' or 'bad' per se: "The decision on whether or not to argue for openness, or for closure, must be an outcome, the result of an assessment of the specific powerrelations and politics" (ibid:167, emphasis original). From a leftist stance, for instance, free flow can be considered 'bad' if it concerns the free flow of capital; from the same stance, closure can be considered 'good' if it is performed by locals attempting to protect their territory. Massey concludes that "both openness and closure, and both classic territory and rhizomatic flow can be the outcome of sedimented and unequal powerrelations" (ibid:174).

Massey also applies her third proposition to the non-human world. Indeed, one very persistent kind of fixing identity of place she locates is in the frozen imaginations of nature. Mountains, the sea, landscapes are seen as 'having always been there,' and consequently as spaces in which we humans can 'ground ourselves' again. However, as Massey points out, 'natural' places are just as dynamic as 'cultural' places: "The nonhuman has its trajectories also and the event of place demands, no less than with the human, a politics of negotiation" (ibid:160). Such a view of the non-human world raises the question: "And yet, if everything is moving, where is here?" (ibid:138).

According to the proposition to think of space as always in the process of becoming, Massey imagines place, 'here,' as an event:

What is special about place is not some romance of a pre-given collective identity or of the eternity of the hills [but] precisely that thrown-togetherness, the unavoidable challenge of negotiating a here-and-now (itself drawing on a history and a geography of thens and theres); and a negotiation which must take place within and between both human and nonhuman. (Massey 2005:140)

By emphasizing that all social relations have to be renegotiated and re-enacted continually in and through space, Massey's three propositions about space open up the future. These negotiations do not 'take place' on a neutral stage, but rather each place has its own story-so-far; represents both resource and evidence for social practice; and is a setting imbued with power, against the backdrop of which negotiations between trajectories cross each other, be it intentionally or by chance. Vice versa, these embedded practices again (re)produce the meaning of place, and it is this intersection of place, objects and bodies that constitute the driving force behind how we think about a place 
and about the people and objects in it. Massey's is hence a geography that "uproot[s] 'space' from that constellation of concepts in which it has so unquestioningly so often been embedded (stasis; closure; representation)" and settles it "among another set of ideas (heterogeneity; relationality; coevalness... liveliness indeed) where it releases a more challenging political landscape" (ibid:13).

As will become evident in Chapter 3.4 and the interview analyses, Massey's three propositions about space have provided a powerful lens through which to view the context of this study, the interview settings and the narratives generated within them. However, these concepts do less to explain how exactly these "events of place" happen in interactions among Massey's stories-so-far. Despite its focus on the processual character of space, Massey's theory still remains an epistemology rather than an ontology, explaining how we come to know the world rather than how the world actually works. To address the latter question, theorists of the spatial have begun to think about space as a material event, triggering an affective turn that redirects the focus of interest to the material, the ontological and the sensual (see e.g. Baier et al. 2014, Clough 2007). ${ }^{3}$ Among these theorists, Sallie A. Marston, John Paul Jones III, and Keith Woodward (2005, hereafter referred to as Marston et al., see also Jones III et al. 2007) have developed a theory that does not converse directly with Massey but which usefully extends Massey's critique through its shared intention to create room for a progressive politics by disrupting dominant ways of thinking about space.

\subsubsection{A Flat Ontology}

Marston et al. envision a theory that is close to life:

Theory should not ignore the diverse intermesh of languages and desires, the making of connections between bits of bodies and parts of objects; sentences half-caught, laws enforced prejudicially and broken accidentally: for it is here, in the middle of the event - at the sites of singular composition rarely resembling discrete and unitary objects - that one finds the production of social space. (Marston et al. 2005:423)

Marston et al.'s argument is embedded in a different debate than Massey's. The authors mainly write to challenge the ubiquitous and politically momentous epistemological segmentation of space into scales in human geography (and in migration research, as I have argued elsewhere, see Büchler and Richter 2010). At the heart of this 'scale debate' has been the insight that geographical scales - ranging from the body to the home, the neighborhood, the city, the rural, the nation, and the globe (to name but a few of the most adamantly contested scales within the discipline) - do not in any way mirror a material reality but are produced through power-saturated representational practices (Marston 2000). As has been shown widely, the social construction of geographical scale

3 Among these theories are notably also Bruno Latour's Actor Network Theory (Latour 2005), Nigel Thrift's non-representational theory (Thrift 2007), Brian Massumi's theorization of affect (Massumi 2002), and Gilles Deleuze's notion of assemblage, as adopted for instance by Jasbir Puar (Puar 2005 and 2007). 
works to organize, segregate, inscribe, and control space, and, in the process, it subjugates, disciplines, and excludes certain bodies. Today the debate exposing the social construction of scale has become so central to geography that it has sometimes been proclaimed to represent geography's single most important contribution to social theory in the context of the so-called spatial turn (e.g. Jonas 2006).

The spatial turn refers to the growing interest of scholars from broader social and cultural sciences in the spatial, triggered by the proliferation of discourses around globalization. Spatial turn proponents argue that due to the global intensification of social relations (faster, over longer distances, more often, etc.), new questions have to be asked regarding the relationship between society and space. In the wake of this discussion some geographers have argued, as I do here, that this new enthusiasm for spatial theory is accompanied by a multiplication of often under-theorized spatial terms and metaphors. The uncritical use of such metaphors frequently falls into a 'territorial trap' (Lossau and Lippuner 2004) as they tend to conceptualize space as exactly the preexisting, static container of social actions Massey takes issue with.

The ensuing ontological turn or affective turn, which has begun to engage more deeply with all things 'everyday' and 'material,' is arguably in the process of 'overtaking' scale as geography's heralded unique contribution to social theory. Marston et al.'s paper is representative of the kind of work associated with the ontological turn. These authors demonstrate that there is no agreement among scale theorists as to what 'scale' actually means or how it could be operationalized, even after several decades of theorizing the concept. At the same time, they discern a trend towards a complication of the term, and especially a destabilization of strictly hierarchical conceptualizations of scale. This undoing is represented by scholarship that seeks to locate social processes and agency by combining hierarchical versions of scale with horizontal - network - theorizing, as exemplified by Eric Swyngedouw's concept of 'glocalization' (Swyngedouw 1997) or by work like Massey's (to whom Marston et al. also refer to in this context), which frames the local and the global as inter-penetrated.

By contrast, Marston et al. bluntly propose to "eliminate scale as a concept in human geography" altogether and install a flat alternative in its stead (Marston et al. 2005:416). Their proposition is motivated by four critiques of the current scale debate, which they consider to have hit a dead-end: First, scale theorists' failure to convincingly theorize the difference between horizontal scale (size, networks, extensiveness) and vertical scale (level, hierarchy). Second, the impossibility of disentangling scalar hierarchies from the distinction made between micro and macro. Third, the trend (both in the critical scale debate and in broader human geography) to assume that scales and their hierarchies are conceptual givens (here the authors enumerate the body, the neighborhood, the urban, the regional, the national, and the global as the 'usual-suspect' scales). This, the authors argue, predetermines structure and content of research endeavors rather than inviting serious reflection on social practices. And lastly, they critique the inherence of an 'objective' or God's Eye perspective in hierarchical scale thinking (ibid:422).

Marston et al.'s radical proposal to extirpate scale as a concept from human geography is not to deny the existence of epistemologies organizing space into scales (or the continued need to analyze the power dynamics inherent in the production of scales). However, they also note: 
Acknowledging the existence of scale as an epistemological ordering frame, however, is not the same as claiming it to exist as a nesting of 'legal, juridical and organizational structures' [quoting Kearns 2004 pers. comm.]. For one encounters these 'structures' not at some level once removed, 'up there' in a vertical imaginary, but on the ground, in practice, the result of marking territories horizontally through boundaries and enclosures, documents and rules, enforcing agents and their authoritative resources. (Marston et al. 2005:420, square brackets original)

With their proposal to abandon the concept of scale in human geography the authors seek to undermine the "army of affiliated binaries" that has attached themselves to the local/global binary, such as place/space, concrete/abstract, agency/structure, empiri$\mathrm{cal} /$ theoretical, culture/economy, responsible/detached, static/dynamic, and subjectivity/objectivity, among others (ibid:421). They criticize that terms such as larger scale forces' ignore "the everydayness of even the most privileged social actors who, though favorably anointed by class, race and gender, and while typically more efficacious in spatial reach, are no less situated than the workers they seek to command." The use of such large-scale descriptors tends to shift the blame to "up there' and somewhere else (the 'global economy'), rather than on to the corporate managers who sign pink slips" (ibid:421,427, emphasis original). ${ }^{4}$

At the same time, Marston et al. critique the figures of "flowsters and globetrotters" that increasingly replace notions of fixity and categorization. Drawing on a language of flow, fluidity, and movement, these concepts often create an impression of absolute deterritorialization (for instance by negating the impact of cultural context) and openness. Marston et al. decidedly reject the voluntarist trajectories often transported through such work, which, they argue, ignore coagulations, blockages, and assemblages only to eventually reassert the scalar scaffold as a 'context' of the allegedly unfettered flows (ibid:423).

Not in order to deconstruct scale, but in order to bypass the four problems they associate with current theorizations of scale, Marston et al. present a possible avenue of un-thinking scale that builds on thinking of space in terms of a flat ontology. A flat ontology discards local-to-global and center-to-margin continua and instead designates "an ontology composed of complex, emergent spatial relations" (ibid:422). It consists of self-organized systems in which "dynamic properties of matter produce a multiplicity of complex relations and singularities that sometimes lead to the creation of new, unique events and entities, but more often to relatively redundant orders and practices" (ibid:424). In other words, through repetition and variation in the practices of its - like in Massey's work both human and non-human - agents, these systems are productive of both systematic orders and creative events. The systematizing events are thereby more frequent than the creative events due to the "tendency for variations to cluster and become generally repetitive," and because creative events are "seldom the actualizations of a genuinely open newness." A flat ontology is hence a geography of the banal.

With "spatial reach" Marston et al. mean that the social site of corporate boardrooms "depend[s] upon a vast distribution of resonating social sites" (ibid:427 - the concept of the social site will be explained in a moment). In other words, the decisions of a corporate executive are spatially more expansive than those of people who are endowed with less power. 
In this approach, to overcome globalizing ontologies, sustained attention is required to grasp "the intimate and divergent relations between bodies, objects, orders and spaces. Given these, we propose that it is necessary to invent - perhaps endlessly - new spatial concepts that linger upon the materialities and singularities of space" (ibid:424).

Marston et al. draw on Theodore R. Schatzki's concept of social sites to elaborate on their flat ontology. Social sites are dynamic self-organizing event-spaces composed of bodies, doings and sayings:

Schatzki's conceptualization of social sites illuminates dynamic contexts that allow various inhabitants to hang together in event-relations by virtue of their activities. He situates this in contextual milieux of tendencies composing practices and orders, noting that 'Things tend not to form random aggregates of continuously metamorphosing matters, but instead hang together as clusters of interrelated determinate stuff' (Schatzki 2002:1). (Marston et al. 2005:425)

In other words, rather than rejecting any notion of order, Marston et al. use the social site in their line of argument to incorporate and explain the effects such orders may have on localized practices. At the same time, they retain the social site as an emergent property of interacting agents:

Leaving room for systemic orders avoids the problems attendant to imagining a world of utter openness and fluidity that inevitably dissolves into problematic idealism. Further, this approach allows us to avoid falling into the trap of naive voluntarism by embedding individuals within milieux of force relations unfolding within the context of orders that constrict and practices that normativize. (Marston et al. 2005:424, emphasis original)

As an example, Marston et al. refer to the layout of the built environment, a collection of objects that - in relation to a human lifespan - changes rather slowly and can therefore have a structuring effect on the social practices in relation with it.

Marston et al. further draw on Gilles Deleuze's concepts of the virtual and the actual. The virtual may be circumscribed as the field of potentialities of what might happen in any space-time, or, alternatively, looking at an event that has already happened, the field of what might have happened (which could be likened to Massey's connectionsnot-made, loose ends). It is out of this vast multiplicity of possibilities that something actually happens, is actualized. The actual, then, is a selection of the virtual, a process by which the virtual is repeated but ultimately differs from itself. Marston et al. frame this dynamic between the virtual and the actual as "an animation of the ways that a site might be considered a conduit for both repetitions of similar orders and practices and the emergence of new, creative relations of singularities" (ibid:425). As in Massey's conceptualization of space, the future is radically open.

Importantly, in a flat ontology the space of the site emerges materially within its event-relations. In other words, a social site does not have a clear border but rather inhabits a 'neighborhood' of emerging practices, events, and orders, which leaves "the emergence of space folded into its own intimate relationalities" (ibid:426). At the same time, emerging practices, events, and orders in social sites are also busy interacting with emerging practices, events, and orders inhabiting other contemporary sites. Marston 
et al. argue that these two aspects - the emergence from the within and from the between - help to resist predetermining a site's contents, as the concept of scale tends to do. "In contrast, a flat ontology problematizes a world in which 'all contemporaneous lives' (Schatzki 2002:149) are linked through the unfolding of intermeshed sites" (ibid).

Using the example of discourses around globalization, Marston et al. discuss potential political implications of their flat alternative. They argue that a flat ontology precludes the "macro-mystifications" that situates blame in 'the structure' rather than holding responsible actual, embodied people, such as immigration officials, politicians, and so on, who enact their functions from within the social sites of interview rooms, corporate boardrooms, governmental offices, and other power-imbued sites. Structural talk, the authors contend, leads researchers, policymakers, and you-and-me-people to believe that the world is helplessly subjected to globalization and dictated by the global capitalist economy. Attaching globalization to social sites works against this assumption and infuses 'the local' with possibilities for upsetting hegemonic narratives of globalization.

In sum, Marston et al.'s reflections reveal the ways in which conceptualizations of the world as being organized into bounded scales from the local to the global significantly limit our field of vision as to how the world works, and especially our visions of how it could work differently. Instead, thinking of the world as flat - as void of any verticality, a mesh of a multiplicity of interactions and emerging social sites - makes room for a progressive politics to emerge. As Marston et al. conclude:

And if [...] we lose the beauty of the 'whole thing' when we downcast our eyes to the 'dirt and rocks,' at least we have the place - the only place - where social things happen, things that are contingent, fragmented and changeable. (Marston et al. 2005:427)

To conclude, the aim of this sub-chapter has been to expound upon the notion of space that has both directed the conceptualization of this study and arisen from working on it. Drawing on Doreen Massey's and Sallie A. Marston et al.'s theories of space as two "trans-communicating conceptual zones" (Marston et al. 2005:423), this study is framed as an embodied geography. More specifically, it is an embodied geography that conceptualizes space as crossings of bodies and their ongoing stories; it treats space as both a resource for and evidence of the negotiations among these bodies and stories. It is a rigorously performative and processual notion of space, in which inheres an element of possibility and creativity that radically opens the future. At the same time, it rejects both over-enthusiastic notions of mobility and flow and preemptive condemnations of closure. As a flat geography, it frames case studies not as an illustration of the effects of an order 'up there' (the global, space, structure, and so on) but as an - and indeed the only - opportunity to study the very production and deployment of such orders. 


\subsection{Traveling Concepts of Sexualities: Queer Migration Studies}

\subsubsection{Queer Theory}

This sub-chapter offers a brief introduction to basic principles of queer theory that have been central to the formulation of the objectives of both queer migration studies and geographies of sexualities. Based on the insight that sexualities and sexual identities ${ }^{5}$ are complex and fluid rather than classifiable in a heterosexual/homosexual dichotomy, the queer perspective emerged in contrast to gay and lesbian studies, which tend(ed) to be organized around essentialist notions of homosexual identities (De Lauretis 1991, Sedgwick Kosofsky 1994). Queer theorists instead work towards developing a decidedly antiidentity stance. From their perspective, identities are not neatly delimitable but understood as effects of ongoing and intersectional processes of identification (Somerville 2007:189). 'Queer' is about "the open mesh of possibilities, gaps, overlaps, dissonances and resonances, lapses and excesses of meaning (that occur) when the constituent elements of anyone's gender, of anyone's sexuality aren't made (or can't be made) to signify monolithically" (Sedgwick Kosofsky 1993:8).

Some queer theorists argue that due to its explicit rupture with lesbian and gay studies and their conceptualization of identity, queer theory occupies a unique position within the landscape of social theories that have emerged from social movements. Unlike queer theory, these other movements and theories - such as the women's or the gay and lesbian movement - were originally preoccupied with establishing, naming, and policing one specific social category and subject/identity. However, I argue that such an exceptionalist view of queer theory sustains a rather artificial gap between queer theory and, for instance, postcolonial feminist analyses or critical race studies. Moreover, it tends to overlook the fact that queer scholars often continue to build on earlier work from gay and lesbian studies, often rendering queer research a continuation of, rather than a radical rupture with, lesbian and gay studies. At the same time, queer theorists have no doubt been among the most creative contributors to conceptualizations of the social that are radically open to additional othernesses (Soja 1996) as also envisioned by postfeminist and postcolonial critics.

Among the foundational work that has enabled the development of queer theory is Michel Foucault's History of Sexuality. In it, Foucault (1978) traces the establishment of homosexuality as an identity back to late $19^{\text {th }}$-century Europe and the subsequent deployment of the figure of the homosexual in order to police the line between 'normal' and 'abnormal' sexualities. Judith Butler's Gender Trouble is another groundbreaking queer theoretical text. In it, Butler elaborates on the mechanisms of the heterosexual matrix. This matrix is based on the constructed binary between sex and gender ('male/masculine' and 'female/feminine') and, importantly, heterosexuality as the 'inevitable' relation

Throughout this study, 'sexuality' refers to sexual/erotic/romantic desires/attractions or sexual acts (none of which need to be tied to the notion of a sexual identity), while 'sexual identity' designates the social identities some cultures establish around same-sex sexual/erotic/romantic desires/attractions or sexual acts; such identities are, for instance, 'heterosexual,' 'tomboy,' 'lesbian,' and others. The border between sexualities and sexual identities is contingent and instable. 
between the two. Butler argues that these are not 'natural' constellations, but cultural constructions normalized by stylized, repetitive performances. These performances are disciplined by discourses molding subjects strictly into either one of these two articulations (heterosexual masculine male, heterosexual feminine female). ${ }^{6}$

Queer theory thus not only disrupts ahistorical, universalist, and monolithic conceptualizations of non-heterosexual sexualities and sexual identities but particularly also queries the (hetero)sexual norm. This critique has been enabled by the formulation of the concept of heteronormativity, which refers to "the institutions, structures of understanding, and practical orientations that make heterosexuality seem not only coherent - that is, organized as a sexuality - but also privileged" (Berlant and Warner 1998:548; see also Warner 1991). These authors hence reject the pervasive idea that desire lies outside the discursive and with Foucault treat desire as a "dense transfer point for relations of power" rather than a natural drive (Foucault 1978:103). This means that studies examining sexualities must always also address the geometries of power underlying the perpetuation of heterosexual primacy, by asking who deploys what concept of sexuality or sexual identity to what end. In this sense, 'queer' is not a catch-all term for all those who are not (normatively) heterosexual but instead more fundamentally frames queerness as that which is positioned outside the 'normal,' the dominant, the legitimate.

In the past two decades, queer scholars have begun to discern a shift in the parting line between 'normal' and 'abnormal' sexualities. This is related to the increasing commodification of white middle class gays (and, though to a considerably lesser extent, white middle class lesbians) in Western countries. Far removed from his former image as a harbinger of perversion and death in the early AIDS era, the gay has been uplifted to the status of the wooed consumer. Gay (and lesbian) spaces have become commodified and spectacularized. Especially in the U.S., but also in Western Europe, city marketing strategies heavily capitalize on urban gay (and lesbian) neighborhoods. Today lively gay neighborhoods not only attract cosmopolitan tourists/voyeurs seeking to consume the exotic, but on a more symbolic level have also become predictors for the wellbeing of high-tech industries in U.S. cities; this is known as the 'gay index' (Rushbrook 2002). This process is further related to the civil rights that gays and lesbians have gained throughout the Western world, especially the right to formalize same-sex partnerships and to adopt children or stepchildren. Many gays and lesbians, queer theorists argue, can now lead a quasi-heteronormal life, as consumers, spouses, and parents, in complicity with capitalism and the nation-state.

In this context, Lisa Duggan speaks of homonormativity, which addresses queer complicity with neoliberalism as "a politics that does not contest dominant heteronormative assumptions and institutions, but upholds and sustains them, while promising the possibility of a demobilized gay constituency and a privatized, depoliticized gay culture anchored in domesticity and consumption" (Duggan 2003:50). Following up on this argument, many queer activists contend that such complicit politics aspired by lesbian and gay rights activists thwart the political potential of queerness, since it fails to

6 Other groundbreaking queer theoretical work includes in particular the writings of (in chronological order) Cloria Anzaldúa and Cherríe Moraga (Anzaldúa and Moraga 1981, Anzaldúa 1987), Adrienne Rich (1986), Teresa DeLauretis (1991), and Eve Sedgwick Kosofsky (1993). 
fundamentally question the existence of heteronormative bastions such as marriage, the nuclear family and childrearing as sites of legal and social privilege (Somerville 2007:189, Warner 1999).

Yet, the concept of homonormativity has also met with criticism. Importantly for this study, some scholars have pointed to the lack of attention to the fact that only certain homosexual subjects have access to homonormal lives, and that these subjects are overwhelmingly white, urban, and middle or upper class males in possession of the proper citizenship. This further marginalizes groups such as queer people of color, trans people, people engaging in polyamorous relationships, people creating alternative family forms, or queer working class women. This critique is now becoming subsumed under the term homonationalism, which will be discussed in more detail in Chapter 3.4.3. Other critics have stressed that even people whose lives may become labeled as homonormative are still far from either formal or actual inclusion. As detailed in Chapters 2.2 and 6.2.1, in Switzerland violence against non-heterosexual people persists, as does legal discrimination, although the latter will be diminished - if not entirely eradicated - by the introduction of gay marriage in 2022. Persisting discrimination becomes particularly evident in public debates around gay marriage, reproductive technologies, and adoption. Current policies and practices around adoption, for instance, are marked by their continuous (re)establishment of difference, which inter alia results in a deep-set culture of humiliation of same-sex parents effectuated through attendant administrative processes. Some queer critics therefore argue that the discourse of inclusion is in fact a "fiction of inclusion" that stands in contrast to legally secured and actually performed inequalities. ${ }^{7}$

In sum, 'queer' is increasingly being used to designate sexual positionalities that not only contest hetero- but also homo-normativity (Browne et al. 2007:12). It is exactly this engagement with the (shifting) lines of that which is naturalized as 'normal' and that which is constructed as its necessary 'abnormal' counterpart that puts queer theory in a position to potentially destabilize all identity claims, not just those based on sexuality. This transforms queer theory into a methodology rather than just a 'theory about gay men and lesbians.' In this sense, 'queer' defines itself 'against the normal rather than [merely] the heterosexual" (Warner 1993:xxvii). Because queer theory postulates that sexuality permeates all areas of the social, sexuality must always be part of a queer analysis; as such, a queer perspective is always necessarily also about sexuality. At the same time, a queer analysis is never only about sexuality, since queer theory frames sexualities as always already, for instance, gendered (Butler 1990), classed (Cohen 2005, Taylor 2009), racialized and ethnicized (Anzaldúa 1987, Stoler 1995), or entrenched in neoliberal conceptualizations of the subject (Duggan 2003). ${ }^{8}$

7 Pers. comm. with Patricia Purtschert, March 5, 2020 (emphasis added).

8 This proposition places queer theory in close proximity to theorizations of intersectionality as discussed in Chapter 3.2.2, a theoretical affinity that has, surprisingly, largely remained unexplored to date. This may be connected to the fact that intersectionality, somewhat in contrast to its emergence from a queer women of color critique, has largely been appropriated by gender studies, which, as some queer theorists have argued, sometimes fail to engage with sexuality (Boellstorff 
However: Despite queer scholars' love of all things fluid, instable, intersectional, and complex, until recently queer scholarship has rarely engaged with the implications of international migration on conceptualizations of sexuality (Manalansan 2006, Somerville 2007), and has only of late begun to view sexuality through the lens of the postcolonial critique in order to address the fact that "sexuality is not only not essence, not timeless, it is also not fixed in place; sexuality is on the move" (Sánchez Eppler and Patton 2002:2). Departing from this insight, scholars from various disciplines have begun to engage with how sexualities move, and what this means. It is to this body of work that I turn next.

\subsubsection{Queer Migration Studies: An Introduction}

Queer migration scholarship que(e)ries both migration studies and queer theory. On the one hand, queer migration scholars have worked towards inserting postcolonial and transnational configurations of sexuality into theorizations of 'queer.' On the other hand, they have sought to salvage sexuality from migration studies, where sexuality has often been problematically conflated with other realms of the social, especially with gender-related issues such as reproduction, motherhood, and family life (Manalansan 2006). This work has demonstrated the significance of unpacking how and to what effect most non-queer migration scholarship continues to configure migrants as always already heterosexual, reifying heteronormative framings of subjects, institutions, social practices, cultural production, economies, consumption, political activism, and research (Luibhéid 2004, 2005, 2008a, and 2019, Manalansan 2006).

It is worth noting that the emergence of queer migration scholarship has been enabled by a broader shift in migration research away from predominantly economic explanations for flows of migration and 'macro' theories based on simplistic push-pull models and a homo oeconomicus (i.e. the assumption that people act solely on the basis of logical cost-benefit calculations). Feminist and postcolonial migration scholars have been instrumental in realigning the focus of migration studies with analyses addressing issues such as identity and identification, agency, and transnational networks on the one hand; and a radical critique of globalizing economies and neoimperialisms and resulting social inequalities on the other. Importantly, this new migration scholarship has not been about either conducting 'micro' analyses (of processes of identification, for instance) or a critique of 'macro' structures (such as 'economy'), but both at the same time, effectively disrupting the micro/macro binary. Lionel Cantú (2002), for instance, used oral histories by people working in the Mexican gay tourism industry to analyze the interconnections between global economies and the commodification of gays. Here, sexuality, which is popularly conceived of as the 'intimate' or the 'private' does not represent the 'micro' nor the tourism industry the 'macro' level, but rather exposes the two as mutually constitutive.

2007). Dietze et al. (2007) offer a rare discussion of the theoretical parallels and differences between the ways queer theory and intersectionality frame the interlacing of social categories. 
In an introduction to queer migration studies, Eithne Luibhéid frames this emerging body of scholarship as engaging in a "double movement," which echoes these two objectives of broader critical migration studies:

On the one hand, [queer migration] scholars have contributed to understanding the experiences of migrants who identify, or become identified by others, as LCBTQ (or, as discussed by the authors in this volume, tomboys, queens, malungos, novios, and amigos, among others). Thus queer migration scholarship insists on recovering, theorizing, and valorizing histories and subjects that have been largely rendered invisible, unintelligible, and unspeakable in both queer and migration studies [...]. On the other hand, much of the scholarship also makes clear that 'queer migrants' in many ways comprise 'impossible subjects' with unrepresentable histories that exceed existing categories. This leads scholars to foreground and challenge regimes of power and knowledge that generate structures of impossibility where particular groups are concerned, and to examine how individuals negotiate them. (Luibhéid 2008a:171)

The present study seeks to perform such a "double movement." On the one hand, it engages with migration biographies and everyday lives of queer migrant women in Switzerland, producing original empirical data on a subject position about which not much academic knowledge exists, and this pertains to both Swiss and international literatures. In general, queer migration scholars have quite rarely relied on ethnographic data to date. More work has employed a cultural studies perspective to analyze queer diasporic positionalities (e.g. Fortier 1999, Gopinath 2005, Muñoz 1999) or has worked towards deconstructing dominant narratives around the intersections of queerness, racism, sexism, the War on Terror, nationalism, neoliberalism, colonialism, and imperialism from a discourse analytical perspective (e.g. El-Tayeb 2011, Haritaworn et al. 2008, Luibhéid 2002, Miller 2005). Among the existing ethnographic case studies, most have focused on gay men in Northern American diasporas (see especially Cantú 2009, Decena 2012, Manalansan 2003 and 2014, and Peña 2013; all on queer diasporas in the U.S., but see e.g. Thielen 2009 on queer Iranian refugees in Germany). The focus on Northern American contexts also persists throughout the handful of works addressing queer immigrant women. This work has mainly portrayed the lives of queer immigrant women from Latin America, though also, if to a much lesser extent, from other world regions. ${ }^{9}$ Further, there has been some research addressing LGBT migrants in general (e.g. Chávez 2011, Lee and Brotman 2011). Outside Northern America, ethnographies on queer migrant women are even scarcer (exceptions include Avrahami 2007, Kuntsman 2003, 2005, and 2009, and Peumans 2018). In Switzerland, contributions addressing queer migrant women are limited to a handful of publications focusing on methodological and theoretical questions and a Master Thesis discussing the biographical narratives of five migrant lesbians (Büchler 2009a, Büchler and Richter 2010, Huotelin 2013).

In addition to queer migration scholarship, this study has been crucially informed by the Queer of Color critique (particularly by work focusing on the German context),

See e.g. Acosta 2008 and 2013, Asencio 2012, Argüelles and Rivero 1993, Barbosa and Lenoir 2003 , Espín 1996, 1997, and 1999, Hidalgo and Hidalgo-Christensen 1976-1977, Leyva Chávez 2000, Luibhéid and Chávez 2020, Mogrojevo 2005, or Poore 1996. 
which does not specifically address sexual dissidents who have themselves migrated as adults but more generally queer people who inhabit, and are assigned, subject positions that are marginalized in mainstream society in terms of gender, gender identity, sexuality, and race/ethnicity. ${ }^{10}$ In this context, some empirical studies specifically addressing diasporic queer people have been commissioned or carried out by human rights organizations, for instance in the U.K. (Safra Project 2002) or in Germany (LesMigraS 2012, Steffens, Bergert, and Heinecke 2010). ${ }^{11}$

That being said, imitating Luibhéid's "double movement," the aim of this study has not only been to acknowledge and make visible the experiences, self-conceptions and practices of queer migrant women, but especially to critically engage with sexuality as a "dense transfer point for relations of power" (Foucault 1978:103). Here, the first concern is to trace how queer migrant women negotiate the multiple mechanisms of exclusion to which they are exposed. In the interviews, these negotiations were not only expressed in narratives about events or places but also in the form of hesitations, a loss of words, refusals, half-sentences, and outbursts. These are the interstices that expose queer women's migrant subject positions as unspeakable and 'impossible,' as normative ideas about sexuality that clash with normative ideas about gender, ethnicity, race, or class are mapped onto one and the same body. The second concern is to gain a deeper understanding of how postcolonial and transnational configurations of sexualities are formative of both non-Western and Western sexualities. Indeed, only once the fixation on the Other is abandoned can postcolonial and transnational circuits of desire and their coagulation with colonialism, neoimperialism, globalization, and neoliberalism be addressed in their full complexity.

\subsection{What's Space Got to Do with It? Geographies of Sexualities}

\subsubsection{Sexuality and Space: An Introduction}

The analysis of the ways in which space and sexuality constitute each other through the material everyday enactment of social relations lies at the heart of the field of geographies of sexualities (or queer geographies) and of this study as well. Drawing on prominent strands of thinking in broader social, political and cultural geography concerned with

10 See e.g. Ani 1999, Castro Varela and Gutiérrez Rodríguez 2000, Gutiérrez Rodríguez 1999:117ff, ElTayeb 2003, 2011, and 2016, Haritaworn 2003, 2005, and 2007, Heidenreich 2005, Ipekçioğlu 1992, 1997, 2000, and 2005, or Oguntoya et al. 1986. For the Anglophone context see e.g. Eng et al. 2005 , Johnson and Henderson 2005, or Muñoz 1999.

11 The Safra Project report focuses on LBT who identify as Muslim. The two studies in Cermany more broadly address the multiple discriminations to which diasporic LBT people are exposed in Germany. These latter studies are partly or fully quantitative. As María do Mar Castro Varela, leading scientist of the LesMigraS study rightly points out, statistical analyses are hard to align with the differentiated queer postcolonial debates around intersectionality and the deconstruction of stable (sexual and other) identities as they necessarily rely on predefined identity categories (LesMigraS 2012:10). 
the ways in which the social production of space and identity are interlaced, geographies of sexualities are specifically concerned with the spatialities of sexuality and the sexualization of space.

Early engagements with sexuality and space worked specifically towards putting sexual minorities on the disciplinary map, drawing on and contributing to lesbian and gay studies to direct attention to geographers' failure to include gays' and lesbians' experiences in theorizations of the spatial, as well as to point out homophobia within geographical institutions. ${ }^{12}$ While a number of these early works date back to the late 1970 , there seems to be a common understanding among queer geographers ${ }^{13}$ that geographies of sexualities became established as a sub-discipline with the publication of David Bell and Gill Valentine's seminal collection of essays Mapping Desire in 1995 (Bell and Valentine 1995b). In the introduction, the editors critically reviewed some of the earlier literature about sexuality and space, taking issue with essentialist ideas about 'gays and lesbians' and 'their spaces' permeating much of this work; the almost exclusive focus on Western and urban contexts in geographical scholarship addressing sexuality; the failure of this work to theorize queer space and the queering of space; and the shortage of work on the spatialities of heterosexualities (Bell and Valentine 1995a). Paralleling the broader transition from gay and lesbian studies to queer theory, geographies of sexualities, too, have undergone a 'queer turn.' Although the insertion of LGBT experiences into geographical thought has remained an important focus of queer geographies, this change of paradigm has catapulted geographies of sexualities from its existence as a 'minority geography' onto the agenda of broader social, political, and cultural geography, as a growing body of work engaged with the mutual constitution of sexuality, space, and identity, fruitfully complicating the literature focusing on processes of identification.

Despite its emphasis on its departure from gay and lesbian geographies, much queer geographical scholarship continues to draw on gay and lesbian studies, risking becoming complicit in perpetuating the very exclusions criticized in earlier geographical engagements with sexuality: First, despite the fact that 'queer' provides the theoretical tools to study a broad range of sexualities, geographies of sexualities have often remained preoccupied with examining specifically gay and lesbian experiences and spaces; still relatively few studies engage with, for instance, bisexuality (Wood 2010), transgender (but see e.g. Doan 2007), sex work (but see e.g. Hubbard et al. 2008), or dissident heterosexualities such as polyamory. Second, considering queer geographers'

12 For contributions about homophobia in geographical institutions, see e.g. Bell 2007 or Valentine 2000 (1998).

13 I use the term 'queer geographer' throughout this study to indicate an embodiment of the researcher. While it remains a fact that many who research the spatialities of sexualities identify as lesbian, gay, bisexual, trans, or queer, there is a growing number of geographers who do not. This, the widening of the field to include analyses of heterosexualities and the (albeit slow) incorporation of queer theory into broader geography is turning the 'queer geographer' into an increasingly ambiguous figure. Can the Straight Guy have a Queer Eye?, asks Phil Hubbard (2007), voicing the uneasiness of many queer theorists with where 'our' theory is heading, which had originally been sparked by the desire to shock-expose the inherent heteronormativity of social practices, theories, spaces, and geographical institutions. 
emphasis on the importance of the contextualization of the sexual, and, more surprisingly, seeing geography's deep implication in, and engagement with, colonialism and globalization, it is curious indeed that until quite recently queer geographies have only rarely engaged with postcolonial critiques and related fields such as queer anthropology, queer diaspora studies, or queer migration studies. ${ }^{14}$

After a brief note on the state of Germanophone queer geographies, this sub-chapter continues to highlight those debates within queer geographies that step into conversation with this study's objectives, such as how to map lesbians (Chapter 3.3.3), and how spaces and sexualities are mutually constructive (Chapter 3.3.4). It then traces migration and postcolonial research within geographies of sexualities and situates this study within this body of work (Chapters 3.3.5 and 3.3.6).

\subsubsection{A Note on Germanophone Geographies of Sexualities}

Queer geographers based in Canada, the U.S., and the U.K. seem to consider their area of research a "consolidated" sub-discipline (Oswin 2010b). ${ }^{15}$ Already in 1999, Jon Binnie referred to the field as a "rapidly expanding area of publication" (Binnie 1999:175). More recently, queer geographers have referred to geographies of sexualities as "a strong and vibrant part of urban, cultural, political, and feminist geographies" (Brown 2004) and as a "proliferating field of study" (Browne et al. 2007:1), with Phil Hubbard suggesting that "one could [...] suggest that [...] queer theory has attained the status of a normalized discourse within the discipline" (Hubbard 2007:151). The extent to which queer theory has been mainstreamed in the discipline of geography seems to be such that it has caused queer geographers to begin to fear the effects of its normalization (Oswin 2005b).

While I am not convinced that queer theory has reached all the places where it can make a difference even within Anglophone geography (see also Oswin 2010b), it is beyond doubt accurate to describe Anglophone queer geographies as thriving visà-vis Germanophone geography, where studies about the spatiality of sexuality have remained insular. The first time I ever heard the words 'lesbian' and 'sexuality' uttered in a classroom at the Institute of Geography at the University of Bern was towards the very end of my Masters studies in the year 2000. A group of German, Swiss and Austrian feminist geography students to which I belonged had invited Doreen Massey to Switzerland for a lecture and a reading weekend. It was one in a series of what turned out to be six annually held Doreen Massey Reading Weekends and lectures, which this group organized in different locations throughout Germany, Switzerland, and the Netherlands between 1999 and 2004. These events were explicitly designed to create a space to "discuss issues (beginning with queer theory) that could not be discussed within the German academy and to do so in a way which was open, questioning, cooperative and based

14 For more comprehensive overviews of geographies of sexualities see e.g. Bell and Valentine 1995a, Binnie and Valentine 1999, Brown et al. 2007, Oswin 2008, and Johnston and Longhurst 2009.

15 Further below I describe these geographies as 'Anglophone,' meaning queer geographies written in English and originating in research institutions in North America, the U.K., and 'Down Under.' While there are differences in the geographies produced in these loci (Knopp 1998), this is not the place to discuss these, or the fact that there are few recognized Anglophone geographies of sexualities originating from other regions, such as Africa or the Caribbean. 
on friendship" (BASSDA 2006a:173). ${ }^{16}$ However, these meetings have remained among the most important efforts to introduce queer theory in Germanophone geography and have not been followed up by the establishment of queer investigations within the discipline.

Hence, the dearth of Germanophone queer geographical research leads Swiss, German, and Austrian queer geographers to turn to Anglophone scholars, theory, methodology, and institutions to approach our fields of interest. ${ }^{17}$ But, as this study attests, queer theories do not travel lightly. This project has been a balancing act between attempts at translating concepts I deemed powerful analytical tools that spoke to the data generated in this project (yet still often refused to fit in many ways) and others I chose to reject or challenge for their - often implicit - reference to predominantly U.S. and British contexts and literature. The pitfalls have been obvious: How can we draw on Anglophone queer geography without situating Germanophone geography as 'backward' in relation to it? How can we avoid naturalizing Anglophone theory as the overarching, abstract and superior framework while relegating Swiss research to a lesser-valued status of the contextual, empirical, local, exemplary? Time and again, I found myself 'waking up' amidst the literature I was immersed in, wondering how to extract leverage for the Swiss diasporic context. The desire to put my cross-cultural theoretical and methodological considerations and the findings of this research into conversation with Anglophone queer geographers was pivotal to my decision to write this book in English. At the same time, this was a paradoxical move, as it has made this study complicit in the very dearth of German contributions to queer geography and queer migration scholarship that I criticize here. ${ }^{18}$

16 We have recounted the story of these reading weekends in BASSDA 2006a and 2006b.

17 As does, for instance, French queer geography, as anecdotal evidence suggests: In June 2010, a workshop was held in Paris entitled "15 ans après Mapping Desire, où en sont les géographies des sexualités?" - "Mapping Desire, where are the geographies of sexualities?". The flyer featured the by now paradigmatic golden belly button adorning the cover of Mapping Desire, and the program boasted many of the 'usual suspects' of Anglophone geographies of sexualities as participants, including a range of authors that had contributed to the anthology Mapping Desire.

18 I have, however, juxtaposed this study with a number of publications and contributions in Cerman (Büchler 2009a and 2009b, Büchler and Jakob 2009, Büchler and Richter 2010, Büchler et al. 2007). Also, I find the accusation of complicity that I have been confronted with repeatedly easy to offer from an Anglophone perspective and dismissive of the very pragmatic problems queer geographers in Cerman-speaking countries face. To my knowledge, this study was the first explicitly queer geographical or queer migration research project ever funded by the Swiss National Science Foundation SNSF. The lack of a Switzerland-based research community resulted in very concrete issues, such as a dearth of books in the field and a lack of access to specific journals in Swiss libraries. At times, this has led to absurd situations in which I found myself trying to craft an argument based on a certain book section by using the haphazardly published teaser pages on Coogle Books and Amazon (which, thankfully, sometimes published a different set of pages of a specific book). 


\subsection{3 (The Problem of Mapping) Lesbian Spaces and Communities}

Based on the assumption that the lifestyles of gay men differ systematically from those of heterosexual people and hence also have their distinct social, cultural, and political spatial patterns, early work on sexuality and space focused on mapping gay residential and commercial spaces in U.S. cities (Lauria and Knopp 1985). These geographies were soon criticized for being inherently male geographies that rendered lesbians invisible. While early commentators reduced the relative invisibility of lesbians in public space to lesbians' lesser access to economic and social capital due to their double oppression as women and lesbians (Castells 1983, Wolfe 1992), ${ }^{19}$ feminist queer geographers more fundamentally called into question the very way of understanding queer urban space in gay geographies, which precluded an analysis of the spatialities of lesbian lives other than in terms of a lack/absence. These scholars particularly criticized geographers' invocation of a public/private divide in which the public is privileged over the private and their narrow definition of gay communities as spatially bounded, publicly visible concentrations of gay people, bars, clubs, and so on (Rothenberg 1995).

By looking differently, lesbian geographies started to emerge. This work not only falsified the assumption that there are no spatial concentrations of lesbians in (U.S.) urban spaces $^{20}$ but also, more importantly, sought to develop alternative ways of thinking about communities, spatialities, and visibilities. For instance, lesbian communities were shown to hinge less on public visibility than on informal and plural networks and institutions, rendering them communities mainly to those "in the know" (Rothenberg 1995). Others argued that lesbian communities had a "quasi-underground character" and were "enfolded in a broader countercultural milieu" that do not necessarily have their own public subculture or territories. This was explained by the historical involvement of lesbians in the women's movement. It was, in other words, shown that lesbians tended to be more politicized than gay men and therefore, at least partly, also chose not to make their communities manifest in a commercialized subculture (Adler and Brenner 1992:31, quoted in Bell and Valentine 1995b:6). Subsequent work in North America, Britain, and France confirmed these findings, and in Switzerland, too, such countercultural milieus have been documented (Amlinger 2005, Kokula and Böhmer 1991, Moser 2001).

Tamara Rothenberg and Gill Valentine have therefore suggested to frame lesbian communities as 'imagined communities,' whose existence hinges less on their visibility in the urban landscape than on a collective imaginary of its members as to what constitutes this community. The term was coined by Benedict Anderson (1991) and has been described as follows: "As 'members' of an imagined community, people feel an attachment to a necessarily fictional group, be it nation, race, gender, class, or sexuality.

19 Seeing the persistent and significant discrimination of women in Switzerland in term of salaries; labor division; and access to the job market, careers, and pension funds, this argument has retained a lot of explanatory power in the Swiss context.

20 In contrast to some places in the U.S., in Switzerland there are no urban neighborhoods that are known as distinctly lesbian. However, through private networks, sometimes clusters of lesbians living in the same house or area are created. 
In the process they interpret themselves through that attachment, so that their subjectivity becomes inseparable from constructions of 'we-ness"' (Weston 1995:257, see also Anderson 1991, Rothenberg 1995, Valentine 1995a).

However, despite this increasing sophistication of lesbian geographies, queer geographers still largely failed to address that lesbian spaces and communities - and the geographies about them - are mostly and implicitly configured as middle class (Taylor 2007 and 2008) and white (Held and Leach 2008, Held 2009, Oswin 2008, Thomas 2010). Building on the notion of the imagined community, Kath Browne, Jason Lim, and Gavin Brown suggest investigating lesbian spaces in the following way in order to bypass the conceptual dead-end of 'mapping lesbians':

Geographies of lesbian space can only be advanced through an attention to women's social networks and their daily circulation through quotidian urban space. We believe that such a project would not just enable a better understanding of lesbian space, but would also reveal the complexities of the everyday geographies of queers of color, gay men who do not participate in the commercial gay scene, and others who are rendered invisible through the focus on fixed territories. (Browne et al. 2007:8)

Browne et al.'s approach is indicative of the 'queer turn' in queer geographies, and also of the intersectional perspective I have attempted to bring to this study. Enabled by the anti-essentialist views on identity as for instance theorized by Judith Butler and Michel Foucault, queer geographers have become less focused on locating gays and lesbians and instead have begun to examine the mutual performative and discursive production of sexuality and space. It is to this work that I turn next.

\subsubsection{Queer Bodies and the Performativity of Space}

Judith Butler theorizes gender and sexuality not as an essence of what one is, but as a "repeated stylization of the body, a set of repeated acts within a highly rigid regulatory framework that congeal over time to produce the appearance of substance, of a natural sort of being" (Butler 1990:33). Feminist and queer geographers have taken performativity a step further, arguing that not only identities but also spaces need to be understood as coming into being through their repetitive performance (Gregson and Rose 2000, Nash 2000, Rose 1999, Valentine 2002). Performances cannot take place in already existing locations, because these locations themselves do not exist prior to their performance. Such a view understands space as both an enabling and disciplining resource and outcome of the performance of identities, "brought into being through performances and as a performative articulation of power" (Gregson and Rose 2000:434). From this, it follows that the production of identities and space are mutually constitutive, rendering both necessarily unstable, relational, partial, and provisional.

This perspective has provided theoretical leverage to address the ways in which spaces are sexualized. "This understanding of space is important," Gill Valentine emphasizes, "because it denaturalizes the presumed heterosexuality of everyday spaces. The straight street or office environment do not preexist their performance, rather, specific performances bring these places into being and these places are themselves performative of particular power relations" (Valentine 2002:154). In other words, spaces 
become inscribed as heterosexual only through the repetitive performance of heterosexuality in them - couples holding hands, advertisements selling products to parents, men whistling after women, and so on. Through their excessive repetition over time, these performances lead people to expect heterosexual performances in said spaces. It is at this point that heterosexuality becomes normalized. In order to secure this semblance of the heterosexual as the 'natural,' regulatory discourses discipline bodies to play out the 'proper' performance. These regimes work through a host of articulations such as laws, social norms and sanctions, 'cultural traditions,' and taboos.

However, since the straightness of spaces is contingent on its repetitive performance, it is also unstable. As Lawrence Knopp and Michael Brown note, "heterosexism is an incomplete, incongruous, nonhegemonic, and spatially diffuse set of social relations and practices full of possibilities for subversion and reconfiguration, rather than [...] a coherent, complete, spatially fixed, and hegemonic one" (Knopp and Brown 2003:413, emphasis original). Since the straightness of space is always in the process of becoming, it can also be queered, for instance by non-heterosexual people, who have a number of according strategies at their disposal. For instance, queering space can be avoided by performing a heterosexual identity; or it can involve non-heterosexual performances addressing only those 'in the know' by employing specific subcultural objects, body language, or practices, such as wearing a single earring in the right ear, playing a certain piece of music in public, or exchanging that knowing glance on the streets. It can also be effectuated by more obvious strategies, such as openly carrying a rainbow pendant on a key chain, or holding hands or kissing in public; or it can consist of politically motivated in-your-face tactics like gay parades, kiss-ins, and so on. (Which is not at all to insinuate that all of these strategies can be freely chosen or performed at all times by all non-heterosexual people.) The queering of space thereby performs a double movement: On the one hand, it effectuates visibility and acknowledgement of the existence of the diversity of sexualities and sexual identities that are otherwise suppressed. On the other hand, it shock-exposes the hegemonic heterosexuality of space.

The practice of queering space is closely linked to the notion of the closet, the spatial metaphor that signifies concealment/invisibility of non-heterosexual people and sexualities. Queer geographers who have examined the space of the closet have addressed its unstable and often contradictory meanings and the complexities of its workings. Diane Fuss (1991, in Valentine 2002), for instance, points out that, paradoxically, to come out means to simultaneously call into being a closet. Similarly, Eve Sedgwick Kosofsky notes:

The presumption of heterosexuality in everyday life is so strong that it is difficult, if not impossible, for a lesbian and gay man to come out, because new closets are continually springing up around them every time they meet a new person and must once again make the decision about whether to disclose or conceal their sexuality. (Sedgwick Kosofsky 1990:157, paraphrased in Valentine 2002:157)

What has largely failed to be addressed by these authors is that because the closet and the attendant practice of queering space are closely tied to the notion of homosexuality-as-identity and the homosexual as a figure, it is an inherently Western concept that does not necessarily translate easily to non-Western and transnational configurations 
of sexuality. For instance, as has emerged in this study, the 'closet' is sometimes also positively connoted, not as a confinement but as a place of safety and privacy (see Chapter 5.3.1). At the same time, David A. B. Murray warns against romanticizing such seeming absences or positive reconfigurations of closets as they often remain, at the end of the day, related to homophobias, which he frames as diversely configured as sexualities themselves (Murray 2011, see Chapter 3.4). In diasporic contexts such as the one examined in this study, this raises the question of how queer migrants negotiate such multiple understandings of in/visibility in their everyday lives. However, the concept also needs problematizing from within a Western perspective, for instance in terms of its applicability or meaning for different generations of same-sex loving women in Switzerland, or for women living in the country versus the city. The sexualization of the country versus the city is the focus of the next sub-chapter.

\subsubsection{Migration in Geographies of Sexualities (The Gay Metropolis I)}

Migration has been at the heart of geographies of sexualities from their very beginnings. Writing in the early 1980s, John D'Emilio already established a link between the development of gay communities and the turn-of-the-century migration to urban areas (D'Emilio 1983, see also Rubin 1993 [1984]). This work was significantly bolstered by the landmark essay Get Thee to a Big City by social anthropologist Kath Weston, in which Weston discusses what she terms the "Great Gay Migration" of lesbians and gays from rural areas in the U.S. to the big cities in the late 1970s and early 1980s (Weston 1995). Weston frames the city as an imaginary, collectively conjured "homeland" that not only fuels lesbian and gay migration, but also and more fundamentally functions as a crucial constituent of homosexual identity. Given "the peculiarly western construction of homosexuality as an identity capable of providing a basis for community," Weston argues, the act of going away from home to forge a liberated, outspoken homosexual Self in urban gay (and lesbian) communities is bound up with what it means to be a homosexual today (ibid:255).

Weston's argument particularly resonated with queer geographers, many of whom have since agreed that "non-normative sexuality is often tantamount to spatial displacement" (Puar et al. 2003:386). ${ }^{21}$ Others have gone a step further, arguing that displacement is a prerequisite to know oneself as gay, and that "it [...] isn't enough to just open the closet door; one had to leave its interior for a different location," either figuratively or physically (Brown 2000:50).

References to Weston seldom mention that she ends her article by complicating matters. In her conclusion she addresses the mismatch that freshly arrived migrants

21 Caren Kaplan (1996:8, as quoted in Puar 2002a:125) has generalized this argument, contending that experiences of location and displacement are central to the constitution of the modern subject overall. This raises the question of how queers are different. Addressing this question, Puar suggests that "travel, in its metaphorization, history, and facticity, [might be] more important to the development of certain queer (cosmopolitan?) identities than of other subjects, perhaps because of the mandate to disrupt heteronormative space" (ibid:125). 
often experience between the city of their imaginations and the city they actually encounter upon their arrival, often resulting in estrangement and disappointment. As one of Weston's respondents soberly assessed, "gay people weren't like me much at all" (ibid:269). Weston convincingly argues that while such counter-narratives effectively work against the establishment of simplistic grand theories of rural-to-urban gay migrations, they do not destabilize the imaginary of the gay homeland per se:

In their very departures from the conventional narrative of gay migration, these counterexamples illustrate the ways that rural/urban contrasts are bound up with the creation of an imagined community peopled with gay subjects. Even at their most dispirited, migration tales tend to be framed by an account of what the narrator originally expected to find. Whether introduced by words of surprise, satisfaction, disillusionment or disappointment, the stories confirm the power of participation in a sexual imaginary at the very moments they dispute its existence. (Weston 1995:269)

Such disruptions between the imaginary gay metropolis and its realities, further fueled by the onset of investigations into rural queer sexualities, have led geographers to differentiate the model of rural-to-urban gay migrations. Ethnographic work bearing witness to lively queer rural communities or lesbians happily living in the countryside unsettled the notion of gay migrations as unidirectional movements from the homophobic-rural to the tolerant-urban, while other writings more fundamentally took issue with the conceptualization of the coming out as a 'once-and-for-all emergence' from the rural-closet to the urban-gay-homeland. As alternatives, these scholars have formulated multidirectional models of queer migration and framed the coming out as a continuous process of negotiation rather than a one-time event (Raimondo 2003).

Taking the proposition that displacement is constitutive of homosexual identity a step further, Larry Knopp examines ontologies of place, placelessness, and movement in what he terms queer people's "quests for identity" (Knopp 2004). In his view, displacement of the queer subject from the family home is required no matter whether queer people are rejected by their families or voluntarily leave their childhood homes to 'find themselves,' and no matter whether they were raised in supportive or homophobic families or social environments. Exactly because the utopian spatial imaginaries Weston describes are bound to lead to disappointment (and sometimes nostalgia for the place left behind), Knopp locates many queer people's comfort, pleasure, and "ontological and emotional security" in movement, as well as displacement and placelessness themselves, framing placelessness per se as a "queer practice" (ibid:124). Intrinsic to this practice is self-reflection:

Queers are actively engaged in processes of personal reinvention that intrinsically entail examinations of ourselves and our surroundings. We are keenly aware of the hybrid nature of our existence, and of the highly contingent nature of both our power and the constraints on it. Hence our ambivalent relationship to place and identity, and our affection for placelessness and movement. (Knopp 2004:129)

But the subject of Knopp's analysis remains vague. His references range from "gay and lesbian people" and "queer people" to "especially gay men," and no indication is given as to these subjects' class, race, ethnicity, or country of origin. It moreover remains 
unclear what kind of migration is addressed. Knopp states that "rural to urban migrations of gay men, for example, are particularly common. But so are international, interregional, and intra-urban migrations and movements, as well as a general embracing of cosmopolitanism" (ibid:123). Overall, Knopp's claims arouse the impression that the theory of "affection for placelessness and movement" he postulates for white, middle class, cosmopolitan American gay men's rural-to-urban migration experiences is sweepingly transposed onto all queer migrants and migrations around the globe. By contrast, as will be discussed, the present study based on narratives by queer migrant women suggests that concepts like home, connectedness, and the ability to create a (transnational) sense of belonging are crucial to wellbeing.

Within geographical debates around sexuality, migration and the notion of home, the bias exposed in Knopp's article has remained symptomatic. Deeper analyses of international migration or of postcolonial and transnational configurations of sexuality have long been conspicuously absent from queer geographical analysis. This is the case even despite the discipline's longstanding occupation with the migrations of (Western) queer subjects on the one hand and - looking at geography in general - globalization and colonialism on the other. In the attempt to define what 'home' is to queer people, it was too often forgotten to ask who the queer migrants were that were deployed as models to formulate these theories, and where they were located before and after migration. It is only under conditions of such normalized whiteness and maleness that sexuality emerges as an aspect of identity that can be analyzed in isolation, when in fact sexuality should be framed as always already nationalized, ethnicized, racialized, classed, and gendered.

As Farhang Rouhani points out, while broad discussions of gender and feminist approaches have since found their way into key textbooks and conference sessions in geographies of migration, sexuality and queer approaches are still hardly mentioned (Rouhani 2016:229). To date, a dearth of work on international and female queer migration in particular persists. There is hence still validity to Andrew Gorman-Murray's earlier statement that within geography 'the nature of queer migration - individual migrants' motivations and destinations, and paths, patterns and scales of relocation - remains little studied and inadequately conceptualized" (Gorman-Murray 2007:106). It is in the interest of addressing this research gap in the field of geographies of sexualities that I present this study.

\subsubsection{A Postcolonial Perspective (The Gay Metropolis II)}

Queer geographers' preoccupation with Western contexts is not limited to work on migration. Generally, what has been termed the "de-centering" of geographies of sexualities has long remained focused on the dichotomy between the rural and the urban (Phillips et al. 2000). Pushing against the metropolitan bias in queer geographies, until recently this work has largely failed to recognize that the concept of 'metropolis' is polysemantic; that the metropolis, as a 'center,' is in fact defined against multiple 'margins'; and that, consequently, there is more than one bias to push against. In particular, it is only recently that attention has been paid to the fact that the construction of the gay metropolis not only hinges on a rural but also on a colonial counterpart, a curious 
silence within a discipline that has been deeply entrenched in mapping the world, charting migrations, and analyzing global development. As Natalie Oswin diagnoses, "queer geographers have been surprisingly slow to engage with the global turn that has existed for some time in queer studies outside the discipline" (Oswin 2006:777).

At the outset of this research in 2005 , work combining queer geographical and postcolonial perspectives was scarce within the discipline and mostly remained limited to North American and Western European contexts. ${ }^{22}$ While the past years have seen a surge of publications on these topics in Anglophone geography, in German-speaking geography, such work has remained insular. ${ }^{23}$ But even for Anglophone geography, Robert Kulpa and Joseli Maria Silva state in the recent Routledge Research Companion to Geographies of Sex and Sexualities (Brown and Browne 2016):

[D]are we play the devil's advocate role and say that the queer and feminist epistemologies we represent across many disciplines have yet to face their colonial legacy and their mostly (Northern) American and Eurocentric and anglophone squint? [...] As editors and authors of this section [on decolonizing sexualities], we feel that as geographers, feminists, queer scholars and all in/out-betweeners, we need not only look for 'non-Western' examples of the worldwide diversity. Rather, and perhaps foremost, we must reconceptualize our own practices and 'doing knowledge.' (Kulpa and Silva 2016:141)

Working from theoretical perspectives foregrounding self-reflection and positionality like 'standpoint theory' and 'politics of location,' emerging post- and decolonial perspectives in Anglophone geographies of sexualities call for a postcolonial critique of the power geometries of knowledge production in geography, asking whose knowledge is acknowledged as such in the discipline, and whose knowledge is canonized, cited, translated, and taught in the discipline - and whose is not (Kulpa and Silva 2016). Queer/postcolonial geographers further interrogate how processes of globalization, the coloniality of power, and the social construction of space and sexuality constitute each other, and generally work to undermine the persistent implicit assumption in geographies of sexualities that queer people are white.

Geographers have thus been called to engage with the work done in other disciplines like queer migration scholarship, which over the past two decades have produced a rich literature on non-Western, postcolonial, transnational, and diasporic formations, as well as on circulations of desire, sexualities, and sexual identities (see Chapter 3.2). At the same time, queer/postcolonial geographers are seeking to develop a specifically geographical perspective. As Jasbir Puar, Dereka Rushbrook, and Louisa Schein write, "ge-

22 Among geographers who had already engaged with the spatialities of non-normative sexualities outside the West or in transnational contexts before were notably Elder 1995 and 1998, Gaetano 2008, Kulpa 2014, Legg 2010, Livermon 2013, Oswin 2005a, 2007, and 2010a, Puar 2001, Skelton 1995, and Williams 2013.

23 Indicative of the recent developments of postcolonial perspectives in Anglophone geography is the Routledge Research Companion to Geographies of Sex and Sexuality, which contains two entire sections on Decolonization of Sexualities and on Mobile Sexualities respectively (Brown and Browne 2016). Earlier compendiums on geographies of sexualities had treated postcolonial perspectives on geographies of sexuality only marginally (Browne et al. 2012 [2007]). 
ographers' rich understandings of place, space, and scale offer queer studies the possibility of grounding theorizations of sexual politics and identities in material and everyday landscapes." This, the authors argue, usefully extends existing bodies of knowledge around "queer diasporas, racialized sexualities, and transnationalism; nationalism and the policing of borders; global capitalism and gay subjectivities; and the heteronormative foundations of development ideologies and imperialism" (Puar et al. 2003:387,384).

Queer/postcolonial geographers hence critically review the field of geographies of sexualities, and generally the discipline of geography, through the combined lens of queer and postcolonial theory. They further work to develop a body of literature engaging with the mutual constitution of scales (the home, the nation, the West, the Orient, the South, the globe), concepts related to these scales (like nationalisms, citizenship, belonging, globalization, migration, or colonialism) and social categories (such as race, ethnicity, gender, sex, sexuality, and others). In doing so, queer/postcolonial geographers also seek to contribute to, and extend, queer/postcolonial work outside geography. The next sub-chapter explores such theoretical concepts from a range of disciplines that have emerged from thinking sexuality, migration, and space together.

\subsection{Thinking Sexuality, Migration, and Space Together}

This sub-chapter engages with concepts of sexuality, migration, and space which are situated at the intersection between queer migration studies and queer geographies. Such concepts have not only been instrumental in the conceptualization and implementation of this research, but have also been extended by the analysis of the biographical narratives generated in its course.

\subsubsection{Sexual Citizenship and the Carceral Archipelago of Immigration}

In one of the early articles on sexual citizenship, queer geographer Jon Binnie simply defines sexual citizenship as follows: "Sexual citizenship' means the relationship between the state and sexualized citizens. It is a useful term since it makes clear that sexual identities are regulated by the state; that sexual dissidents do, for instance, not enjoy full citizenship in most states" (Binnie 1997:238). Since the $19^{\text {th }}$ century, the trilogy of heterosexuality-marriage-parenthood has been maintained as the bourgeois ideal and building block of the nation in capitalist societies. ${ }^{24}$ It therefore comes as no surprise that the relationship between states and sexually dissident citizens has typically been vexed. This relationship has come under scrutiny by a rapidly growing interdisciplinary body of queer research, so that the nation-state is today one of the most diversely theorized, contested, and re-enacted geographical scales in queer scholarship. Literature in this field has, for instance, exposed how the state polices sexuality through immigration legislation and other state institutions and practices (e.g. Luibhéid 2002, Miller 2005); how gay and lesbian identities become commodified by nationalized economies,

24 In German, the triad of heterosexuality-marriage-parenthood is referred to as Zelle der Gesellschaft (cell of society). 
cultures, and politics (e.g. Cohen 2005, Duggan 2002, Richardson 2005); how the formation of sexualities and sexual identities is entangled with colonialism and neoimperialism (e.g. Massad 2002 and 2007, Puar 2007, Stoler 1995); and how these relations of power are negotiated, reproduced, and resisted by marginalized queer subjects (e.g. Anzaldúa 1987, Chávez 2013, Manalansan 2003, Muñoz 1999).

In its variety and scope, this research has shown that sexual citizenship does not only play out in the realm of the legal but also in the realm of the social, the political, and the cultural. Importantly, it has also demonstrated that the policing of normative sexual citizenship is often achieved through the establishment and maintenance of an uneven border between the private and the public, as regulated through systems of welfare, immigration legislation, taxation, and so on. The notion of 'public space' is closely connected to the notion of democracy and equal rights for all citizens. Per definition, 'public' spaces should be inclusive spaces accessible to all and should provide an "unconstrained space within which political movements can organize and expand into wider areas" (Mitchell 1995:110, quoted in Duncan 1996). But public space has never been accessible to all, as for example exemplified in the exclusion of women from the right to vote in Switzerland until 1971 (see also Massey 2005:152-153). Today's growing (semi-)privatization of many formerly public spaces (e.g. shopping malls, train stations, etc.) has accentuated and facilitated such processes of exclusion and fueled attendant contestations. In addition, the definition of what is 'public' crucially depends on the definition of its counterpart, the 'private,' creating a dichotomy that is pointedly gendered and sexualized. As Nancy Duncan argues: "The public/private dichotomy (both the political and the spatial dimensions) is frequently employed to construct, control, discipline, confine, exclude and suppress gender and sexual difference preserving traditional patriarchal and heterosexist power structures" (Duncan 1996:128). Epistemologically, the public space thereby represents the (male) space of policy-making, production, mind, culture, while the private sphere signifies the (female) space of home-making, reproduction, body, nature.

State regulators interfere with the private sphere in ways that read as wildly paradoxical if not viewed through the underlying logic of heteropatriarchy. While in some instances, such as domestic violence, state interference continues to be conservative and protective of the private space as private, it has been relentless in invading the bedrooms of sexual dissidents and other minoritized groups, particularly racialized and working class Others. As further confirmed in this study, the state's treatment of homosexuality demonstrates that "the intimate is a coproduction with the public," and that "intimate relations cannot be considered synonymous with the [scale of the] body or the household" but rather must be read as "a site for ordering population" (Oswin and Olund 2010:60,62, emphasis added; see also Richardson 2000). Accordingly, the queer geographical debate on sexual citizenship has centered around issues such as the policing of public sex; the outlawing of homosexual acts even in the private space; and queer activists' 'in-your-face tactics,' which 'queer' space through a queer 'figure of critique' that exposes the heterosexism inherent in normative citizenship (Califia 1994). However, this work has not only been overwhelmingly about men (but see e.g. Nash and Bain 2007): it has also predominantly been about British and U.S. contexts. Also, it has almost exclusively focused on assumed already-citizens, thereby giving little consideration to those 
who are not (yet) citizens (but see Binnie 1997). This is particularly deplorable given queer geographers' engagement with the ways in which the nation-state and sexuality are constitutive of each other. One would expect this consideration to be an especially needed intervention within migration scholarship, where research designs based on national identities continue to constitute the norm (e.g. "Turkish migrant women in Munich," etc.).

Within the debates around sexual citizenship, Eithne Luibhéid's work on the definition and regulation of migrant populations has been particularly influential, and in the context of the present study provides a powerful tool to analyze the power-saturated structuration of queer migrant women's experiences and self-conceptualizations. ${ }^{25}$ In her pioneering book, Entry Denied (2002), Luibhéid draws on the shifting U.S. immigration policies, laws, and practices as archived in court documents and decisions, congressional hearings, immigration-service manuals, exclusionist writings, and newspaper articles to trace the history of the definition and exclusion of specific bodies from legal residence and citizenship in the U.S. according to normative ideas about sexuality. National heteronormativity, she writes, is "a regime of power that all migrants must negotiate" (Luibhéid 2008a:174, emphasis original), no matter whether heterosexual or not. For instance, certain migrant women were excluded from the U.S. because they were subject to a generic suspicion of unrestrained childbearing (as was the case with Japanese 'picture brides' in the early 1900s), while others were barred admission because they were assumed to be involved in 'unmoral' sexual practices, such as prostitution (as was the case with Chinese women in the late 1800s). ${ }^{26}$

Luibheid applies Foucault's notion of the carceral archipelago to analyze how immigrants are tied into a system of surveillance. Rather than being located in one single institution (immigration control), the carceral archipelago works across institutions, procedures, laws, and dominant social groups, for instance in the form of immigration and welfare legislation, asylum procedure, labor market regulations, professional associations, and so on, linking together "bureaucrats, experts, politicians, and the public in new ways, around preoccupations with sexuality, immigration, and nation" (ibid:xv). For instance, Luibhéid analyzes how the former Immigration Naturalization Service, the Public Health Service, and the American Psychiatric Association in the U.S. interacted to establish a visual economics which enabled immigration officers to categorize 'masculine-looking' women migrants as homosexuals and consequently pathologize them as mentally defective, rendering such women deportable until this law was repealed in 1990 (!). As Luibhéid notes, "it was not lesbians and gay men who initially sought to be recognized by the immigration service. On the contrary, it was the immigration

25 In German-speaking queer migration scholarship, Marc Thielen has made a similar argument, see Thielen 2009.

26 Apart from her groundbreaking analysis of nation-states' stake in defining/controlling migrant sexualities, Luibhéid's work is also remarkable because it remains one of the still rare works to date following calls by queer theorists to apply a queer perspective-i.e. an analysis of the ways in which sexuality is mediated through relations of power - to heterosexualities, too, instead of focusing exclusively on LGBT sexualities (see also Hubbard 2007). 
service that sought, in sometimes bizarre and frightening ways, to identify and penalize lesbians and gay men who tried to enter the country" (ibid:ix). In other words, rather than 'discovering' preexisting sexual identities of immigrants, "the immigration service [and other governmental institutions] centrally contributed to constructing the very sexual categories and identities through which women's immigration possibilities were then regulated" (ibid:xi, emphasis added). These are not only tales from the past. "Female sexuality in particular remains bound by socially 'acceptable' notions of femininity," Rutvica Andrijasevic diagnoses in the context of her discussion of the antitrafficking campaigns several Western EU countries have been conducting in Eastern Europe to deter Eastern European women from migrating to Western Europe (Andrijasevic 2009:390). These campaigns equate informal labor migration with forced prostitution, juxtaposed in opposition to home as a safe haven. "By portraying the 'home' as being a place devoid of danger and thus also of prostitution, these campaigns attempt to regulate women's sexuality by placing women within the space of heterosexual domesticity," Andrijasevic concludes (ibid).

These systems of surveillance discipline migrant bodies beyond 'dressing up' for the brief moment of crossing the border (such as cutting or growing your hair, wearing clean and adequate clothes, preparing a normative narrative, assuming a collaborative attitude, etc.): "Foucault's image of the carceral archipelago makes clear that even when the processing of immigrants resulted in their admission, it also situated them within larger relations of power to which they remained subjected after entry" (Luibheid 2002:xv, emphasis added). Luibhéid draws on Robert Chang saying that marginalized groups in the U.S. "carry a figurative border with us," which continues to regulate migrants' everyday lives ever after entry (Chang 1997:249, quoted in Luibhéid 2002:xviii). For instance, migrants must not become dependent on social welfare for a certain period of time after arrival; undocumented migrants live in constant fear of discovery and deportation (rendering them an exploitable work force); and so on.

The carceral archipelago hence organizes sexuality in ways that intersect gender, race, and class to reinforce white, heteropatriarchal supremacy while at the same time relegating multiple marginalized subjects to paradoxical places (see also Luibhéid 2002, Chapter 3). From the biographical narratives generated in this study, several institutions and organizations have emerged as sites where migrant sexualities are defined, disciplined, regulated, and controlled in Switzerland as well. Two of the most dynamic and contested legal frameworks in contemporary Switzerland (discussed in Chapter 2) have become visible as particularly momentous: immigration/asylum legislation and same-sex partnership legislation. Other discourses and practices equally tie into the system of surveillance regulating migrant sexualities, such as regulations, discourses, and practices dominating in integration offices and political parties, the welfare system, psychoanalytical practice, research, and even migrant and LGBT rights organizations.

As Luibhéid stresses, this production and simultaneous policing of sexual identities is often tied to a particular logic of development. Luibhéid argues "evolutionary narratives persistently frame immigrant women's lives and sexualities within models of movement from 'tradition to modernity' and 'repression to liberation' [...]. These models recirculate ahistorical images of immigrant women as backward, passive, and dependent victims of third-world patriarchy" (2002:140). Thus, at physical and imagined national borders, 
sexuality - and female sexuality in particular - becomes a site for drawing and monitoring the lines between who is backward and 'traditional' versus who is 'modern'; who is sick and who is healthy; and who is sexually deviant and who is sexually 'normal.' Ideas about sexuality thereby intersect with ideas about gender, race, ethnicity, and class. These delimitations are productive of exclusionary nationalisms, eventually resulting in the question of who is eligible as a potential future citizen and who is not. The developmental narrative represented here is linked to a larger colonial narrative that is coming under increasing scrutiny by queer scholars. This is the topic of the next sub-chapter.

\subsubsection{Queer Theory Meets Postcolonial Studies: Gay-Friendly 'West,' Homophobic 'Rest'?}

Based on the now commonsensical insight that "physically sexual acts may have varying social significance and subjective meaning depending on how they are understood in different cultures and different historical periods" (Vance 1991:878, quoted in Miller 2005:146), queer anthropologists have been compiling a body of literature about samesex practices and identities across cultures beyond the Western notion of 'gay and lesbian. ${ }^{27}$ However, research on men has dominated this field. As Evelyn Blackwood and Saskia E. Wieringa hold, this predomination is related to same-sex intimacy among women being regarded as "less developed, less common and less visible than male homosexuality" (Blackwood and Wieringa 1999:44). Although female same-sex intimacies have received increasing attention in recent years, these studies remain very unevenly distributed in terms of the geographical contexts they are examining.

The approach that has long prevailed in anthropological research aims to 'excavate' what are conceptualized as 'local,' 'traditional,' or 'precolonial' non-conforming sexualities. As David A. B. Murray contends, such research has taken "a (Margaret) Meadian 'look how open-minded they are' approach, emphasizing how sexual diversity is accepted in certain non-western societies and that 'we' westerners could learn something from 'them"' (Murray 2009:2). This, Murray continues, creates "a significant lacuna in understanding how and why certain sexuality and gender categories and practices come to be taboo, excluded, and/or repellant" (ibid). ${ }^{28}$ Queer postcolonial scholars have since begun to engage with the sometimes highly paradoxical ways in which geopolitical trajectories of power as played out in colonial, neoimperial, and neoliberal times have been implicated in shaping the contexts in which same-sex sexualities are negotiated globally today.

Within this field, there is a trending discourse which pits a progressive, modern, and gay-friendly West against a backward, traditional, heteropatriarchal, and homophobic South and Orient, or 'Rest,' respectively. The foundation for this sexualized 'West'/'Rest'

27 See e.g. Allen 2011, Alexander and Mohanty 1997, Blackwood and Wieringa 1999, Blackwood 2010, Boellstorff 2005 and 2007a, Chalmers 2002, Dankwa 2014 and 2021, Griffin and Mulholland 1997, Cunkel 2010, Jackson and Sullivan 2001, Murray and Roscoe 1998, Sinnott 2004, and Wekker 1997. 
binary was laid during $18^{\text {th }}$ and $19^{\text {th }}$ century colonialism. Scholars que(e)rying sexualities in this period have demonstrated that the formation of sexual norms in the West during that time "cannot be charted in Europe alone" (Stoler 1995:7). The installation and maintenance of heteronormativity in this era did not only depend on its demarcation from the figure of the white/'Western' homosexual but was importantly also defined against an exoticized, sexualized colonial 'savage' (Stoler 1995). ${ }^{29}$ This construction of the colonial subaltern as a sexual Other was not only instrumental in legitimizing the endeavor to civilize 'savage' and 'backward' subjects, but also in facilitating the systematic exploitation of enslaved women's and men's labor and bodies (Stoler 2002). In other words: The colonial 'savage' was always also defined in sexual terms - without race, no sex, without sex, no race. As Laura Ann Stoler notes, "colonialism is that quintessential project in which desire was always about sex, that sex was always about racial power, and that both were contingent upon a particular representation of nonwhite women's bodies" (Stoler 1997:43). This cornerstone of colonialism - the co-constitution of race and sex - has persisted into the postcolonial era (e.g. Cohen 2005, JanMohamed 1992, Somerville 2000). It manifests in the persevering stereotypes conveyed by currently strengthening nationalist discourses, which for instance frame male racialized migrants as sexually aggressive and threatening to (especially white) women, or which depict Asian women alternately as sexually compliant or aggressive. Such racialized sexualizations and their effect on queer migrant women's lives will be discussed in more detail in Chapter 5.1.4.

But what has recently led Western nationalisms to include (certain) homosexual subjects in their folds? And, vice versa, what is pushing leading political and religious figures and media in many countries such as for example in India, Malaysia, Uganda, Nigeria, Ethiopia, Russia, and Jamaica ${ }^{30}$ to condemn homosexuality as a manifestation of Western decadence and hence as inherently 'unnatural' to Indian, Malaysian, etc., 'tradition' and 'culture'? Unpacking these questions is complex and still very much ongoing in queer postcolonial scholarship, and this introductory chapter cannot provide a full discussion of this issue. What follows is instead a handful of examples and considerations on (post)colonial configurations of sexualities which aim to qualify and complicate the claim currently proliferating in Switzerland that many non-Western 'cultures' (especially allegedly the African, Muslim, Balkan, and Eastern European 'cultures,' but also South European 'culture') are homophobic in essence.

I take the global negotiation of 'African' genders, gender relations, and sexualities as an example (aware, of course, that there is no such thing as a unified African understanding of gender or sexuality). For this context, queer postcolonial scholars have exposed the deep implications of colonial continuities in the current rise of homophobias in many African countries. In particular, it has been demonstrated that these homophobias also have to be read as a result of persistent homophobic colonial Christian morale and legislation; the quickly increasing visibility of gay and lesbian activism

Complicating this argument, Siobhan Somerville argues that the Western figure of the homosexual emerged not only parallel to but in fact crucially also through discourses of racialized bodies (Somerville 2000). 
around the world and the global circulation of the figure of the homosexual through the media, the internet, tourism, and migration; and of the current virulent anti-gay activism propagated by U.S. evangelical churches in various African countries (e.g. Binnie 2004, Gupta 2008, Murray and Roscoe 1998). Further, these homophobias must be understood as effects of global cultural, economic, political, and military power geometries that have framed, and continue to frame, 'Africa' and 'Africans' (like, especially, 'Muslims') as backward and inferior. It is also against such persisting denigration and very real global inequalities that masculinist nationalists in former colonies and other countries outside the West have established the figure of the homosexual as an example of Western decadence while simultaneously framing homosexuals as essentially 'Un-African' (or 'Un-Indian,' 'Un-Bosnian,' etc.).

It is well researched at this point that nationalisms are highly gendered (e.g. YuvalDavis 1997, and see especially Purtschert 2019 for a recent account of Swiss gendered and racialized nationalisms). However, to date, far fewer scholars have investigated how nationalisms and national identities are always also sexualized. Among them is Gayatri Gopinath, who in her work on queer diasporas specifically aims to "dissect the ways in which discourses of sexuality are inextricable from prior and continuing histories of colonialism, nationalism, racism, and migration" (Gopinath 2005:3). Gopinath acknowledges the existing feminist postcolonial body of work on gender and nation showing how "female sexuality under nationalism is a crucial site of surveillance, as it is through women's bodies that the borders and boundaries of communal identities are formed." Such sexualizations of the nation are valid for all nationalisms. Equally, all nationalisms are racialized as the notion of nation and race (and culture) are intimately connected (see e.g. Jain 2018 and Purtschert 2019 for the case of Switzerland). In more concrete terms, gendered and racialized nationalisms - or, as deconstructivist thinkers have framed nationalisms, imaginations or fictions of the nation ${ }^{31}$ - are crucially established through the figure of the pure, chaste 'national woman' (e.g. the 'Indian' woman, the 'Swiss' woman, etc.). This 'national woman' is depicted as being in need of protection, especially from 'foreign' men (Dietze 2019), and, importantly, is pitted against an inferior 'other' woman - e.g. the 'Muslim' woman.

At the same time, Gopinath criticizes the work of many postcolonial feminists working on gender and nation for failing to fully address "the ways in which dominant na-

31 Thinkers on nation and ethnicity like Benedict Anderson (1991) and Etienne Balibar (1991) have exposed the nation-state not as a product of but instead as productive of ethnicities and nationalities. In this view, nationalities and ethnicities emerge from nation-states, not vice versa, because nation-state formation happens through the imagination of national communities. As Balibar writes about his notion of "fictive ethnicity": "No nation possesses an ethnic basis naturally, but as social formations are nationalized, the populations included within them, divided up among them or dominated by them are ethnicized - that is, represented in the past or in the future as if they formed a natural community, possessing of itself an identity of origins, culture, and interests, which transcends individual and social condition" (Balibar 1991:96). Nation-states are hence imagined spaces and material territories mutually constituting each other. The national space also becomes "a cultural cipher of an obligatory full inclusion," which works on the principles 'all or nothing' and 'either or.' This renders culturally hybrid positionalities impossible (Nassehi 1990:270, quoted in Mecheril 2003:25). 
tionalism institutes heterosexuality as a key disciplinary regime," while remaining "curiously silent about how alternative sexualities may constitute a powerful challenge to patriarchal nationalism" (ibid:9, emphasis added). In other words, an explicitly queer perspective on nationalisms is needed to expose how the 'national woman' is constructed as always already heterosexual. The naming of this seemingly obvious fact is crucial precisely because of its perceived banality, since it demonstrates how the heterosexuality of the 'national woman' is naturalized to the point of invisibility. This catapults the queer female citizen into the realm of the impossible: It is not possible to be both 'lesbian' and 'Bosnian,' for instance. While it has - arguably - become possible for certain white lesbians who (can) live up to homonormative ideals to be both 'lesbian' and 'Swiss,' many queer women in Switzerland - such as queer migrant women, trans people, or queer women living in non-monogamous relationships - remain excluded from this homonormative Swissness and its attendant privileges. ${ }^{32}$ What this impossibility means for the self-conceptions and experiences of queer migrant women in Switzerland, and how queer migrant women's presence in Switzerland as queer and ethnicized/racialized women affect the global negotiation of sexual norms, will be discussed throughout this book.

For now, I want to return to the example of 'African' sexualities, and specifically Murray's warning not to romanticize precolonial African societies as communities in which variant genders and sexualities were practiced and acknowledged throughout. If we do look at investigations into precolonial African sexualities, these reveal a vast array of patterns of understanding and doing genders, gender relations, and sexualities. In many cases, these did, and sometimes still do, include the acknowledgement of variant genders, gender roles, and sexualities (Murray and Roscoe 1998). While this work certainly effectively debunks the myth that same-sex sexuality in Africa has foreign origins, it (particularly) also exposes the sheer difficulty to think and write about precolonial understandings of gender and sexuality within the framework of 'modern' Western science with its specific understandings of these concepts. Nevertheless, this ample evidence of precolonial alternative understandings of gender and sexuality further testifies to the immense effects of the colonizers' attempts to force the European bi-gendered heteropatriarchal system, the attendant categorization and pathologization of differently gendered and sexualized people as sexual Others, and the equally attendant subjugation of women onto colonial communities (Oyěwùmí 1997; similar processes have also been described for other contexts, see e.g. Lugones 2007 for the example of Native American communities). This heteropatriarchal system was again also intrinsically racialized, as it established vastly different arrangements for colonized males and females (as located both in- and outside the colonies, for example in slavery or indentured worker contexts) on the one hand, and for male and female white bourgeois colonizers on the other (Lugones 2007:186).

But things are even more complicated. Heteropatriarchal anti-colonialists and nationalists in (ex-)colonies often collude(d) with and maintain the establishment of such

32 As discussed above (Chapter 3.2.1), some queer critics argue that in the face of persisting discrimination and violence against homosexuals in Switzerland, it is more apt to speak of a fiction of homonormative inclusion here. 
European heteropatriarchal orders (Gopinath 2005, Lugones 2007). This perspective on the agency of subjugated populations connects to another concern voiced by scholars who have criticized some queer postcolonial work for its replacement of homosexuality with homophobia as 'Evil of the West.' Postulating that homophobia in the South or in the Orient is an import from the West once more reconfigures the West as the actor and the colony as the passive surface upon which the colonizers' scripts are written. Critics of such a view have unmasked this as a multiple misconception. First, such a perspective effaces differences within the (ex-)colony. As Gayatri Spivak points out speaking on the context of colonialism in India: "The Indian Aboriginal did not flourish in pre-British India [...] there is something Eurocentric about assuming that imperialism began with Europe" (Spivak 1999:37, quoted in Castro Varela and Dhawan 2003:273). Second, both in the colonial and in the postcolonial era, same-sex practices or identities in the (ex-)colonies have not resulted from a unidirectional diffusion of ideas about sexuality from the metropolis to the colony, but have instead emerged from a process of contestation and negotiation between colonizers and native populations on the one hand and different perspectives on sexuality within each of these groups on the other (e.g. Jackson 2001, Manalansan 2003).

In order to clarify and illustrate my point on the complexities of (post)colonial configurations and global negotiations of sexualities, I turn to Serena Dankwa's examination (2014 and 2021) of female same-sex intimacy in urban Ghana. Over the past few years, LGBT organizations have grown stronger in urban Ghana, not least through financial and ideological support from Western organizations. As in other African countries, the increased visibility of gay and lesbian rights advocacy has been accompanied by a marked rise in homophobia decrying homosexuality as a Western import. At the same time, Dankwa found that Ghanaian LGBT activism and activists - mostly males - have remained rather disconnected from urban working class women living female same-sex intimacies. These women sometimes use the term 'doing supi' to refer to their samesex intimacies, which are framed as a practice rather than a sexual identity. However, these intimate concepts and formations of female same-sex intimacy are not 'local,' 'genuine,' or 'untouched by colonial rule.' For instance, Dankwa describes that same-sex practices operate on the basis of discretion rather than confession. This is related to both the historical respectability of discretion in Ghanaian culture as well as to women's fear of growing homophobia. Also, while the ways in which these women conceptualize their same-sex practices and relationships indeed partly refer to older West African cultural figures and terms of kinship (such as the figure of Mami Wata or the figure of the sister), historically the term 'doing supi' probably has its roots in the ways in which female same-sex bonds were enacted at Christian boarding schools. ${ }^{33}$ Dankwa further views these intimacies through an economic lens. To working class women in Ghana, same-sex relationships, just like opposite-sex relationships, are always also a matter of bare necessity. To 'make do,' all relationships, including intimate ones, are a crucial

33 Incidentally, the Swiss Basler Mission ran such schools. This and other only recently told tales, for instance of Swiss colonial trade businesses, configures Switzerland as highly complicit in the colonial project, see Chapter 1. 
means for socio-economic survival. This is one of the reasons why many women entertain (sexual and non-sexual) relationships with more than one partner, often including both male and female persons, at a time. Just as much as they are rooted in 'tradition,' the same-sex intimacies of these urban working class women are hence closely tied into (post)colonial economies and politics.

Dankwa's work also points to the importance of contextualizing the multiplicity of homophobias, in plural, around the globe (Murray 2011). While most of this work is yet to be done, it has already been shown that there are political configurations that do not reiterate the gay-friendly West/homophobic 'Rest' dichotomy. As Tom Boellstorff (2011) shows in his analysis of the perception of sexually non-normative men in Indonesia, violence against such men was extremely rare until the fall of the Suharto regime in 1998, which Boellstorff frames as an example of a postcolonial society that had developed heterosexism without homophobia.

As Dankwa and an increasing number of other queer postcolonial scholars emphasize, the growing 'lesbian' and 'gay' activism in countries outside the West has complicated discourses around a variety of same-sex intimacies. Lesbian and gay organizations both in- and outside the West - among them especially those Western LGBT organizations that have declared it their aim to fight homophobia in developing countries and accordingly support lesbian and gay organizations in these countries - privilege Western definitions of same-sex practices, inserting all sexual dissidents into a developmental narrative in which sexually non-normative people start out as preidentitarian sexual practitioners who are subsequently liberated to become 'out,' politicized, self-identified homosexuals (Altman 1996, Manalansan 1997). ${ }^{34}$ As Joseph Massad argues, this figure of the "Gay International" is "destroying social and sexual configurations of desire in the interest of reproducing a world in its own image, one wherein its sexual categories and desires are safe from being questioned" (Massad 2007:189 and Massad 2002). Massad accordingly associates such politics with a cultural imperialism that projects homophobia on the non-Western Other.

Queer anthropologists have joined this contestation of simplistic models postulating a unilateral globalization of the gay and lesbian identity. As Peter A. Jackson points out in his work on Thailand, while it is true that Western gay and lesbian styles and terminologies are often appropriated to resist local heteronormativity, this strategy does not represent a "wholesale recreation of western sexual cultures in Asian contexts" (Jackson 2001:6). Instead, Jackson postulates a "selective and strategic use of foreign forms to create new ways of being Asian and homosexual" (ibid, see also Binnie 2004). On another note, Martin F. Manalansan (2003) documents how linguistic trends in the queer Filipino diaspora in New York 'paradoxically' make their way from the Philippines to New York and hence flow from the alleged 'margins' to the alleged 'center' rather than vice versa. Still other research is beginning to focus on queer diffusions and contestations within the global South and Orient.

34 At the same time there are, paradoxically, Christian organizations from the U.S. who have declared it their aim to strengthen the anti-gay politics in African countries, so that the entire U.S. pro- and anti-gay debate has now become copy-pasted onto African territory (Koama 2012; see also http://pr ospect.org/article/exporting-anti-gay-movement\#main-content, downloaded on October 11, 2014). 
The origin and rise of heteropatriarchal nationalisms in former colonies in general and homophobic nationalisms in particular must hence be read in their full complexity: as legacies of colonialism; as the ongoing work of neoimperialism and globalizing neoliberalism; and as the work of heteropatriarchy and nationalism, which were sometimes, though not always, forged in the context of anti-colonial movements. In other words, homophobias are far from being 'essential' to, for instance, 'Muslim' or 'African' cultures, as increasingly popular discourses in Western Europe suggest (see next subchapter). Nor are homophobias outside the West as omnipresent as these popular discourses would have it; as discussed earlier, many cultural norms and practices that are affirmative of variant genders and sexualities continue to exist around the globe. Furthermore, 'modern' homophobias do not permeate the entire 'non-West.' In Chapter 2.2.3, evidence to the contrary was provided, such as for example the fact that South Africa was the first country in the world to grant homosexual subjects fully equal rights (which is not to state that there is no homophobia in South Africa - there is); or that for years Mexico was much more progressive in terms of granting homosexual people equal rights than the U.S., contrary to dominant discourses in the U.S. persistently framing Mexico as culturally backward and 'developing.' Many findings of the present study, too, undercut the model 'gay-friendly West' - 'homophobic 'Rest."

It is important to note that this juxtaposition does not only affect former colonies and their subjects, but instead encompasses all places and people that become defined as 'not the West.' As Fatima El-Tayeb writes in the context of the invisibilization of racism she diagnoses for Europe:

The European ideology of racelessness creates a double bind for racialized populations: an internalist perspective claims European exceptionality by defining the continent's identity as both entirely self-generated and self-contained, while a universalist narrative simultaneously presents the European condition as paradigmatically human and other, non-Western parts of the world as inevitably deviating from this norm. (El-Tayeb 2011:81, emphasis added)

El-Tayeb argues that "across the political spectrum, the relationship between the West and human rights is more often than not presented as a necessary, natural one," yet "there is no inquiry whatsoever into why those non-western nations do not support human rights; instead, it is implied that they simply have different values" (ibid:87). One the other hand, no questions are asked about the Western commitment to human rights, such as:

How much is the international human rights system undermined by centuries of exploitation in the name of a humanitarian 'civilizing mission' and how much is this memory kept alive by the open creation of 'extralegal' zones through extraordinary rendition, secret prisons, 'harsh interrogation techniques,' and antiterrorism laws in the West? How important are successes in institutionalizing international human rights regulations when the very concept of 'rights' is becoming increasingly irrelevant within a neoliberal globalization that privatizes everything from wars to health care to prisons - and from which the Western nations profit more than anyone else? (El-Tayeb 2011:88-89) 
In other words, it is not the case that Human Rights are an intrinsic characteristic of Europeanness, which then, as a consequence, necessarily generates a 'culture clash' when Western European culture, constructed as the 'normal,' baseline culture, comes into contact with other, 'particular,' differing cultures because these latter cultures are inherently averse to Human Rights. The problem is instead that 'Europe' constantly violates Human Rights and perpetuates global social injustice, while at the same time managing to maintain moral superiority over societies it positions in opposition to these allegedly essentially European values. In the context of Switzerland, especially Black people, people perceived as Muslims, and people identified as originating from the 'Balkans' and Eastern and Southern Europe become located outside Swiss citizenship through such processes of racialization.

\subsubsection{Homonationalism}

European nations have increasingly come to identify with homosexuality or homosexuals' rights respectively, which over the past two decades has led to the at least partial inclusion of certain homosexual subjects into the folds of Swiss citizenship. But how exactly did this normalization come about, seeing that the 'homosexual' had historically been constructed as the nation's internal sexual Other, and seeing how early European imaginations of the Orient especially also located sexual licentiousness and deviation in the same Orient which has since become framed as essentially homophobic (Haritaworn and Petzen 2014:115, Said 1978)?

While it is certainly true that the past two decades have seen a growing inclusion of homosexual subjects in Western European citizenship, queer postcolonial and queer of color critics are increasingly raising their voices against the fact that this inclusion is not accessible to all sexually non-conforming people. Instead, the inclusion of certain homonormative gays and lesbians into the folds of social normativity and Western European nationalism coincides with an exclusion of other non-conforming queer subjects (Castro Varela and Gutiérrez Rodríguez 2000, Dietze 2019, El-Tayeb 2011). This exclusionary mechanism is part of a larger discourse Jasbir Puar has termed homonationalism (Puar 2005 and 2007), a powerful concept that speaks to how the increasing integration of certain (white, predominantly male, middle class, monogamous) homosexual subjects in Western consumerism and nationalism produces hierarchies related to race, class, gender, and nation-state. The concept of homonationalism builds on and extends Edward Said's notion of Orientalism (1978), which describes the ways in which Western cultural products, academic knowledge, and other discourses construct the 'Orient.' Like Orientalism, homonationalism addresses how Western nations circulate ideas about other cultures, such as especially the 'Islamic world,' 'Russia,' 'Africa,' or 'Eastern Europe' or 'the Balkans,' which establish the West as morally and culturally superior to these other places. Homonationalism also extends the concept of Orientalism by particularly addressing how lesbian and gay rights discourses are increasingly becoming central to the construction of contemporary Western hegemony. The concept of homonationalism is further in dialogue with feminist postcolonial work, which has long made a similar argument in terms of gender. This argument, sometimes referred to as femonationalism, is famously summarized by Gayatri Chakravorty Spivak's remark 
that colonizers' discourses around the colonies have to be understood as a case of "white men saving brown women from brown men" (Spivak 1994 [1988]:93). ${ }^{35}$

The history of the image that the Western world has been crafting of sex in the Orient is a point in the case of how the way in which the Other is constructed changes to serve the delineation of the Western Self against an inferior Other. As Jin Haritaworn points out, "if Said's Orientals brimmed with a rampant queerness and promiscuity that clearly needed restraining, today 'Muslims' are imagined as repressed and not free enough" (Haritaworn and Petzen 2014:115, referring to Puar 2005:125-126).

Puar specifically describes how discourses in the U.S. highlight gay rights and sexual liberalism and deploy these discourses as moral justifications for the War on Terror. Within this logic, gay and lesbian rights serve as a legitimation for the fight against allegedly homophobic Muslim countries and groups, disguising imperialist moves as acts of liberation of homosexual people (and also women) in these countries while at the same time rendering invisible domestic homophobia (along with sexism/heteropatriarchy). In an "insistent and frantic manufacturing of 'homosexuality' and 'Muslim' as mutually exclusive and discrete categories," the terrorist subject becomes a trope for the (re)production of U.S. exceptionalism (Puar 2005:126).

The entrenchment of Puar's discussion of homonationalism in U.S. discourses and practices around the War on Terror and the specific position of the U.S. in the global geometry of power renders homonationalism in Puar's terms only partially applicable to the European or Swiss context (Mesquita 2011). Correspondingly, European scholars have begun to translate the potential of the concept to European contexts. This work has, on the one hand, specifically addressed migration and European diasporic contexts in the U.K., Germany, The Netherlands, and other Western European countries (e.g. Butler 2009, Dietze 2019, Fassin 2010, Gunkel and Pitcher 2008, Haritaworn 2008, Haritaworn et al. 2008, Jivraj and De Jong 2011, Kulpa 2014, Kuntsman and Miyake 2008, Mepschen et al. 2010, Mesquita 2011, Mesquita and Purtschert 2016). These authors have for instance examined naturalization procedures in Western European countries in which immigrants from Turkey and generally from Muslim countries (and only those) are confronted with photographs of homosexual couples or questionnaires featuring questions such as "Imagine that your son comes to you and declares that he's a homosexual and would like to live with another man. How do you react?" (quoted in Gunkel and Pitcher 2008; see also Mesquita 2011:225). Such practices articulate gay rights within the frame of the West/Europe as a space of modernity that needs to be protected against the putative orthodoxies of Muslim immigrants. As Henriette Gunkel and Ben Pitcher argue:

Puar's work has shown that the sexual politics of the War on Terror not only provide a tool for underwriting the moral superiority of its antagonists, but have served a wider function in organizing and shaping a diverse range of mechanisms of inclusion and exclusion, as the terrorist subject is directly linked to the figuration of 'non-integrated' citizens, migrants and their families. In this process, Islam has come to be constituted as one of the main obstacles to successful 'integration' within the West and for the implementation of democracy outside of it. Through this discursive formation, 'the Muslim' is 
constituted as an 'impossible subject' within contemporary nationalist discourses [...]. (Gunkel and Pitcher 2008)

These discourses frame homosexuality as essentially European and the Orient as essentially homophobic. In such framings, not only the Muslim European, but especially also the queer Muslim becomes an impossible subject. Interestingly, as Fatima El-Tayeb observes, the difference between Western Europeans and Muslims is thereby less framed as a conflict between Christians and Muslims - that is, as a religious conflict - than as a conflict "between European humanism, committed to the protection of rights, namely those of gender equality and sexual freedom, and a hostile, intolerant foreign culture" (El-Tayeb 2011:81-82).

Other work within the flurry of queer postcolonial body of literature by Europe-based scholars engaging with homonationalism has revealed that not one but many Others are being produced by these discourses. Beyond the Islamic world, these also include Africa, Russia, and Central and Eastern Europe (CEE) (Kulpa 2014, LeBlanc 2013). Since some participants in this study migrated from CEE and Ex-Soviet contexts, a glance at Robert Kulpa's work is useful. Kulpa (2014) demonstrates in his analysis of discourses within the European Parliament about CEE that CEE "is often framed as the European (homophobic) Other in the emerging discourses of 'homoinclusive EUropean Nationhood"' (ibid:431). However:

Not able to reject CEE as the absolute Other (as it does with Islam) due to the geographical, religious, and cultural proximity, and in the face of the EU enlargement, it is sexuality that provides a new arena for the revival of the West/EUropean orientalism towards the CEE. [...] I argue that gay (human) rights became ostensibly marked as a litmus test of CEE progress towards the West/Europe. (Kulpa 2014:440)

Homophobia in CEE is hence seen as a malady slowing down (rather than threatening as in the case of Islam) the Western European self-proclaimed modernity, but there is "hope on the horizon" for this malady to be cured:

In a leveraged pedagogical gesture of the one who knows better, West/EUrope reprimands CEE first, but then also promises to help in erasing 'the issue.' But the help comes as a strongly conditioned, and an undisputable process that has little respect or interest in the local circumstances of why 'the issue' has arisen in the first place. (Kulpa 2014:440)

Homonationalisms have, in other words, been shown to come in many guises and to be operative across a range of geographical loci in terms of who produces such homonationalisms. Femo- and homonationalist ideas also importantly structure dominant discourses in Switzerland. Anti-Islamic discourses have generally been of an increasing virulence in Switzerland, infamously culminating in the ban of the construction of minarets in the country in 2007 and the national ban on veils in 2021, with both decisions taken by Swiss voters in the context of a people's initiative. As the campaign poster for the anti-minaret initiative in Figure 2 shows, the campaign leading up to the ban of minarets was highly gendered and sexualized. This poster was one of the most 
widespread campaign posters and could be seen in public spaces all over Switzerland. In the form of black missile-like minaret symbols on the Swiss flag, it depicts Islam as threatening, aggressive, expansive, and territory-grabbing. The main threat, however, is placed in the foreground and comes in the form of the veiled Muslim woman. The figure insinuates that the arrival of Muslim women poses a threat to women's rights in Switzerland, erasing home-made misogyny and fueling generalizing notions of Muslim women as powerless victims of their heteropatriarchal societies.

Figure 2: Campaign poster for banning minarets in Switzerland:

"Stopp-Ja zum Minarett-Verbot" - "Stop - Yes to the ban on minarets"

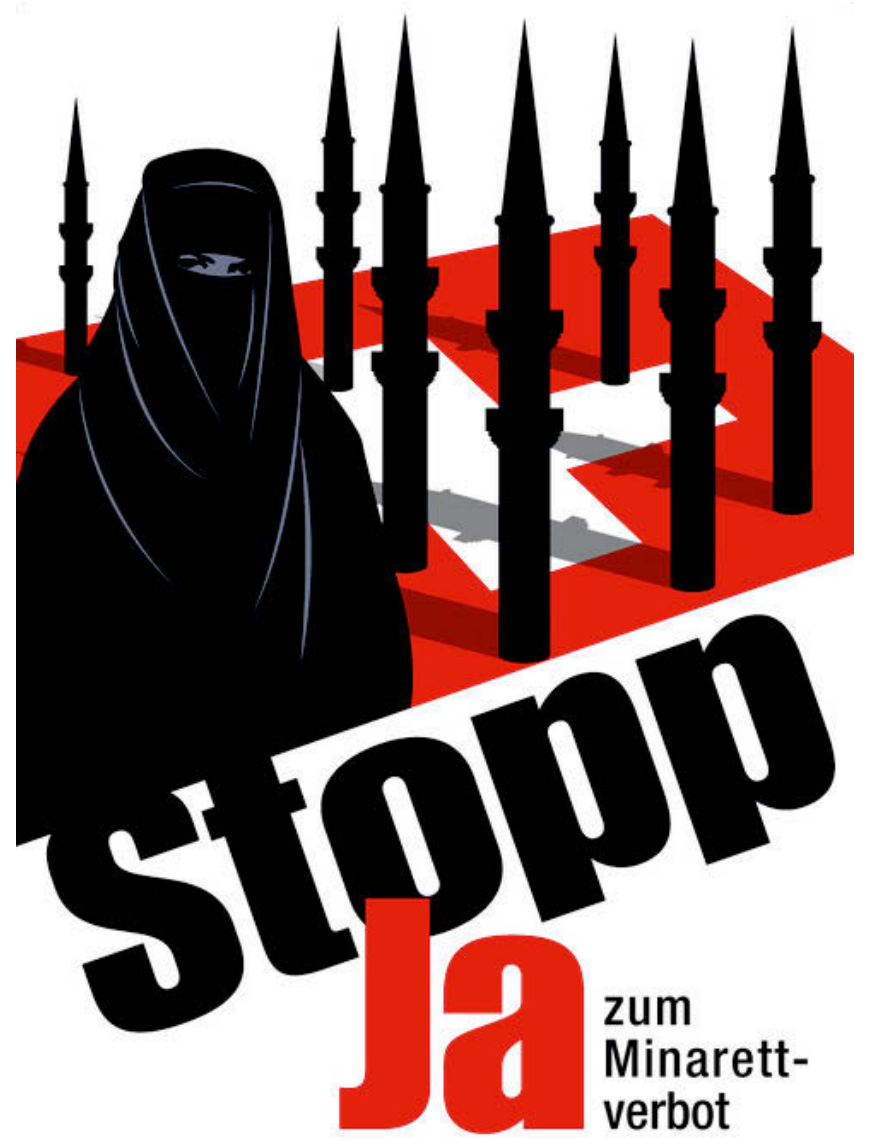

(Source: Schweizerisches Sozialarchiv / Sozarch_F_5123-Pe-157)

Both anti-Islamic discourses and discourses around 'Africans' are frequently also homonationalist. Two examples I would like to cite here are symposia organized by the gay organization NETWORK I attended in the context of the fieldwork. These were entitled "Immigrantenkultur versus Menschenrechte-Homosexuelle im Kul- 
turkampf?" - "Immigrant culture versus human rights - homosexuals caught up in cultural clash?" 36 and "Das Tabu Homosexualität in der Integrationsarbeit-Respekt fördern oder fordern?" - "The taboo of homosexuality in integration work - to foster or to demand respect?". From these titles the immigrant communities in Switzerland emerge as inherently homophobic, and 'Swiss' homosexuals in need of protection from 'them.' Figure 3 shows the flyer of the latter event. The event description starts out with the sentence: "In many immigrant cultures, patriarchy is still as rooted as it was the case with us 100 years ago, and homosexuality is as deeply tabooed as was the case with us 50 years ago." From this as well as the remainder of the flyer text, "immigrant cultures" emerge as backward in relation to Swiss culture (which remains unnamed or only referred to as 'us,' a discursive move that automatically excludes 'immigrants' from this very 'us'). "Immigrant cultures" appear as fixed and monolithic, stuck in patriarchal structures, and essentially homophobic. No part of the text opens the possibility of the existence of liberal attitudes among "immigrants," rendering 'their' homophobia a given. Such a framing of "immigrant cultures," renders queer immigrant subjects impossible subjects: queers cannot exist within such "cultures." Instead of addressing diversity among "immigrants," the flyer contrasts "immigrant cultures" to school children using the word schwul ('gay,' used derogatively, similar to 'faggot') as a swear word in the school yard on the one hand and to the "Catholic church," "evangelical churches," and "Jewish orthodoxy" on the other. It asks whether "we" can morally "ask more" of "immigrant kids" and "immigrant cultures" in terms of respect towards homosexuality, than of these other groups (i.e. the school children and the named religious groups). This comparison simultaneously in- and excludes these other groups. Referring to the homophobia of these other groups, the text asks: "Should we sweep in front of our own door before teaching immigrant kids?" School children and the named religious groups hence seem included in 'our house,' the front of which wants cleaning, while "immigrants" are, by contrast, evidently not even residents of this 'house.' Also, "immigrants" do not appear to be either school children or members of any of the named religious communities. At the same time, these other 'groups' appear as fixed and monolithic as the "immigrant cultures" themselves, as homophobia is externalized onto Others (school children, religious groups) once more. In the text homophobia hence never appears as a problem among (the unnamed) 'us,' the white and allegedly gay-friendly Swiss Self. This underlying assumption stands in stark contrast to the persisting violence and structural discriminations against homosexuals in Switzerland. Also interesting is the fact that the list of invited guests reveals that "immigrants" actually means 'Muslims': Besides the integration officer of Basel city and a (neo)liberal politician from Basel, only the vice president of the Vereinigung islamischer Organisationen in Zürich VIOZ (Association of Islamic Organizations in Zurich), Hasan Taner, and a representative of a Muslim organization from the canton of Basel Stadt were invited to discuss on the podium.

The mechanisms of homonationalism can hence be summarized as follows: In the interest of reproducing a border between the 'Swiss' and its Other within the context of such nationalisms, the nation-state has been forced to make space for a normalized 
Figure 3: Flyer for the event "Das Tabu Homosexualität in der Integrationsarbeit-Respekt fordern oder fordern?" - "The taboo of homosexuality in integration work - to foster or to demand respect?" organized by the gay organization NETWORK, Basel, August 25, 2008.

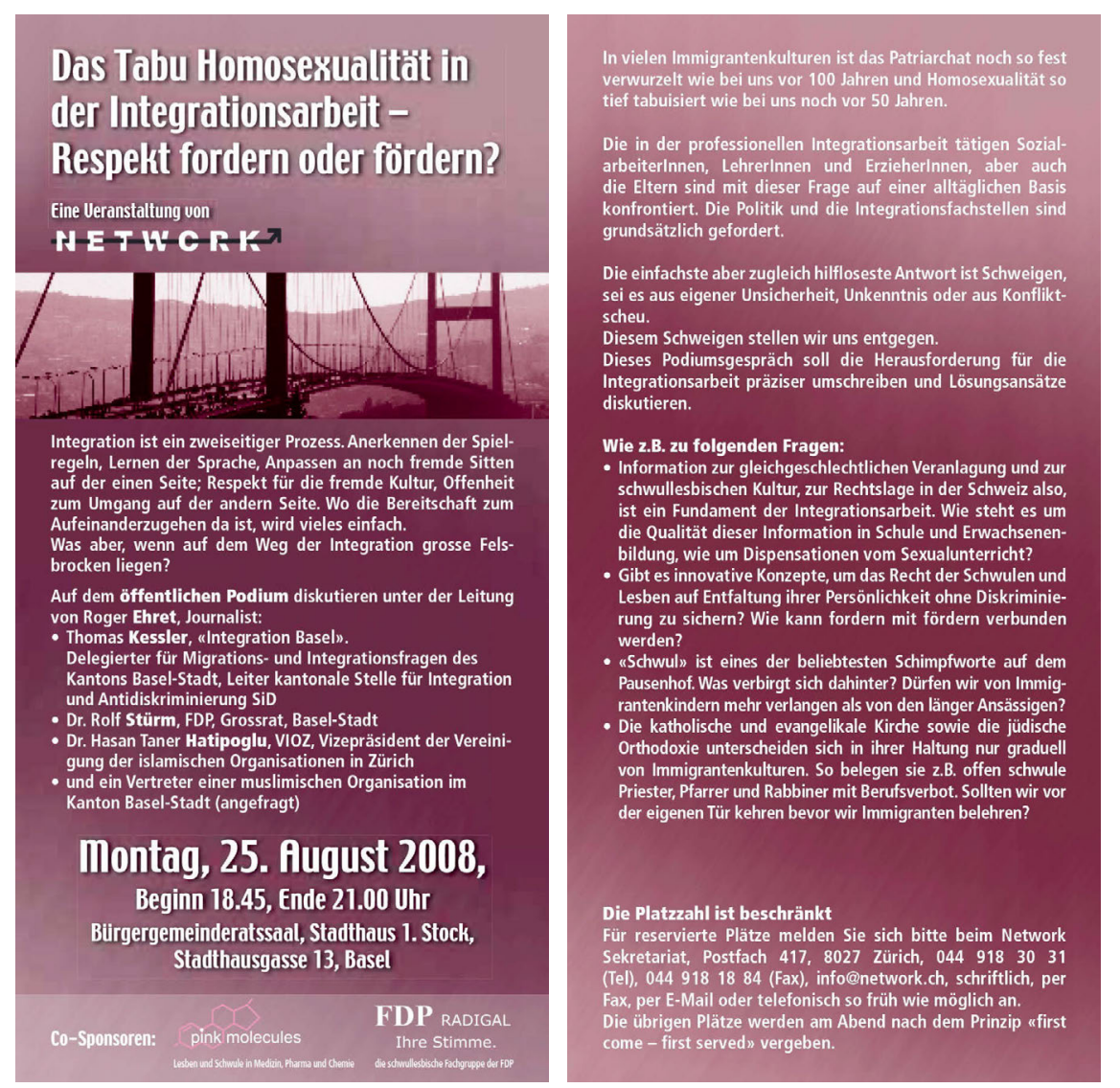

homosexual citizen; this allows the Swiss Self's nation(ality) to uphold its appearance of enlightenment and tolerance. In turn, Swiss homonationalism not only legitimizes aggravated immigration control and discriminatory moves against immigrant people but at the same time effectively effaces the fact that there is continued discrimination and violence against homosexual people within Switzerland - also against those privileged white middle class gays and lesbians who might be eligible for inclusion within the homonational imagination (see Chapter 2.2.2). It is therefore paradoxical that it has specifically also been lesbian and gay rights advocates who have been reproducing homonational discourses, rendering it all the more difficult to sustain critique against structural homophobia among the 'Swiss.' At the same time, such homonationalist discursive maneuvers exclude queer migrants from participating in the ongoing process of normalizing homosexuality in Switzerland, since, as will be shown here, subjects how are both migrant and queer are rendered 'impossible subjects.' 
The past few years have seen the appearance of some critical scientific work about homonationalist discourses in Switzerland. Already in 2011, Sushila Mesquita postulated that the current tendency in Western Europe, including Switzerland, to further fortify the borders against what is constructed as the extra-European Other might have constituted one condition to enable the present acceleration of the recognition of certain normalized gay and lesbian identities within Western Europe. In a critical reading of two poster campaigns, one launched by Amnesty International Switzerland and one by the LGBT rights NGOs Queeramnesty, Homosexuelle Arbeitsgruppe Bern HAB, Pink Cross, LOS, Amnesty International, and NETWORK, Mesquita shows how the poster series frame homophobia as something which takes place 'elsewhere' but not in Switzerland, or something performed by people who have migrated to Switzerland from these 'elsewheres' (Mesquita 2011:222-231). Mesquita extends this argument together with Patricia Purtschert. The authors introduce the notion of gay governance in order to point to how "specific relations of governance, education, salvation and patronaging between queer actors are set up along racialized lines, especially in the context of NGO work" (Mesquita and Purtschert 2016:141-142). In their meticulous reading of a number of LGBT organizations' events, publications, and campaigns in Switzerland, the authors demonstrate the production of a narrative that postulates that homophobia is currently being imported into Switzerland by immigrants, particularly African and 'Muslim' immigrants. Again, through locating homophobia outside Switzerland (but now arriving here through immigrating bodies), these discourses erase Swiss-made histories and geographies of homophobia while at the same time fueling racist notions of certain immigrant populations. As such, these NGO discourses are, often inadvertently, complicit in legitimizing right-wing anti-immigration discourses and ever stricter immigration and asylum policies. These homonationalist developments in Switzerland can hence be summed up in the words of a group of German queer and postcolonial authors, who state that "racism is the vehicle that transports White Gays and Feminists into the political mainstream. The questionable amnesia in which the sudden claim of a European 'tradition' of anti-homophobic and anti-sexist 'values' is grounded is less a result of gendered progress than of a racist backlash" (Haritaworn et al. 2007:188, quoted in Mesquita 2011:227, my translation).

\subsection{4 "Your country has failed you": Queer Asylum}

Within the scholarship engaging with homonationalism or more broadly with the coconstitution of nation and sexuality in a postcolonial context, asylum has drawn increasing attention as a technique of nation-state power that defines, marks, allocates, and disciplines queer bodies (e.g. Lewis 2010 and 2013, Miller 2005). This sub-chapter outlines how queer migration scholars address the ways state politics and LGBT rights organizations are obsessed with and - often unwittingly - instrumentalize queer asylum and the figure of the queer asylum seeker in order to propagate the Western notion of the liberated homosexual Self.

First, state politics: Asylum procedure engages in a paradoxical double move. On the one hand, it requires queer asylum seekers (and their advocates) to forge a 'credible' and extremely clear-cut - in this case sexual - identity in the attempt to situate them- 
selves as members of a clearly defined, prosecuted 'social group. ${ }^{37}$ Like immigration control at large as described above in terms of the carceral archipelago, asylum thus brings into being and reproduces specific bounded subjects and groups, which need to be rooted in Western normative ideas about sexuality and gender to be legible for asylum officials of the receiving nation-state. Moreover, and much in contrast to queer theorists' insistence that sexuality and desire have to be understood as changing, multiple, and contradictory, the demonstrated identities need to be conceptualized as immutable, essential, fixed, and intrinsic to the person and their biography. On the other hand, while an asylum seeker needs to be permanently allocable to a prosecuted social group in order to be granted asylum, asylum simultaneously and paradoxically seeks to individualize and single out the asylum seeker from this social group to prevent alleged floodgate effects.

What is more, through a narrative of "Your country has failed you, you are safe here" (Miller 2005:143, see also Lewis 2010 and 2013), asylum emerges as a self-serving stance of receiving countries in the West. Alice Miller identifies this as a "violent gift" for the individual asylum seeker, who is required to dissociate from, and speak extremely ill of their country in order to receive asylum; they are thereby forced to re-enact once more the dichotomy of a humanitarian and enlightened West versus a repressive and backward South or Orient. Within this logic, the story of how one has become aware of one's homosexuality in one's homeland, and how extremely badly one fared as a homosexual in the homeland, is central to the process of establishing a 'credible' asylum case - and credibility is all-important, as one's story often represents the sole or most important 'proof' of persecution someone can present. ${ }^{38}$ This forced narrative veils several mechanisms of state power. First, it obliterates the ways in which the West engages in flightinducing practices through processes of (neo)colonialism, economic globalization, and other techniques of cultural, political, and military imperialism. Second, it renders invisible the fact that it is actually non-Western countries that host the vast majority of the world's refugees. Third, by restricting the granting of sexuality-based asylum to sexually non-conforming asylum seekers, flight based on heterosexual violence is expunged or conflated with gender-based 'cases.' Finally, this forced narrative once again obfuscates domestic homophobia in Western countries (ibid:143-146). ${ }^{39}$

Second, activism: As already demonstrated repeatedly, LGBT rights organizations in Switzerland and elsewhere unwittingly often contribute to their states' self-congratulatory deportment. Successful (but especially also unsuccessful) queer asylum claims

37 In her powerful analysis of asylum practices in the U.S., Alice Miller more generally remarks with regard to the relationship between asylum procedure and identity that "asylum tends to favor identity as the touchstone of what is essential to protect about the human, and deems only some forms of conduct or behaviors as fitting that identity" (Miller 2005:167, see also Reddy 2005).

38 Besides these narratives, Swiss asylum procedure and practices in queer migrants' asylum cases also hinge on a visual economics that favors feminine men and masculine women, see Chapter 2.3.2.

39 Karma Chávez elaborates on a paradox in her examination of the U.S. government's increasing refusal of asylum to queer asylum seekers from Mexico. These refusals (which often not even made it to court) are based on references to Mexico's 2006 liberal legislation with respect to homosexuality as well as on the argument that "There is now a Cay Pride Parade in Mexico City," suggesting that Mexico is 'catching up' with the U.S. with respect to human rights (Chávez 2010). 
make concrete, quick, and simple to communicate positive (or scandalous) human rights news with a human face. This promise lures activists into "strategic shortcuts" and thus into complicity with discriminatory state procedures (Miller 2005:160). ${ }^{40}$ Writing against such shortcuts, Miller calls for asylum and human rights practices to "become more aware of the implications of contemporary theories of sexuality," that is, to contextualize sexualities and sexual identities rather than to oversimplify and stereotype them; to view sexuality as interacting with other realms of the social (ibid:137,162). The tricky task for activists and advocates is to "minimize the complicity of asylum storytelling with the imperial project, while still being successful in ensuring that those who seek to cross the border can still cross" (ibid:165, emphasis in the original). Of course, the problem is that with the welfare and sometimes life of real people at stake, this is not an apt field for playful experimentation.

To conclude this discussion of citizenship, homonationalism, and asylum: Working through these mechanisms of nation-state power, we need to remain aware that the nation-state is, above all, an epistemological construct, a discourse, a way in which the world is structured to enforce and territorialize certain relations of power whose materializations also have their own effects. As such, the nation-state, just like any other scale, depends on our everyday re-enactment of it; as Sallie A. Marston and her colleagues have pointed out (see Chapter 3.1.2), there is no nation-state 'up there,' beyond our everyday performance of it. And in the 'dirt and rocks' of everyday social practices these re-enactments are, more often than not, flawed, especially (but not only) when performed by 'impossible subjects' such as queer migrant women. As such, non-conforming practices necessarily feed back into how we might change our thinking about nation-states.

While Michel Foucault and Judith Butler and the queer migration scholars who have drawn on their work provide theoretical leverage for the analysis of the role state-based power circuits play in the construction and policing of sexualities and sexual identities, this theoretical framework also presents difficulties for conceptualizing agency and resistance (Luibhéid 2002:162n). As Rutvica Andrijasevic aptly points out, "the overwhelming emphasis in the feminist and queer migration literature on control has led scholars to privilege the analytic framework centered on exclusion in which states enforce migrants' exclusion through refusal of entry at the border, removal through deportation or denial of citizenship" (Andrijasevic 2009:389). However, while all queer migrants are disciplined by, and must negotiate, state power and hegemonic discourses, queer immigrant bodies are not merely passive pawns played by agents of the nation-state or other circuits of power; rather, they are in dialogue with these agents, actively (dis)obeying, appropriating, choosing, and strategizing - and these practices feed back into the system. Unfortunately, scant attention has been paid to the processes that constitute national sexualities in everyday practices as well as to the lived realities of those situated

40 Some Swiss LGBT organizations have since become more sensitive to the danger of outsourcing homophobia to the Other. See e.g. https://www.neuewege.ch/queere-asylsuchende-der-schweiz?s earch=Schweiz, downloaded on January 7, 2020, for a contribution by two Queeramnesty activists who reflect on these pitfalls (Ott and Navarra 2019). 
at the deprivileged end of the uneven distribution of economic, cultural, and political power both within and among countries (Oswin 2006). As this is one of the main gaps this study seeks to address, the following sub-chapters engage with more embodied concepts from queer migration scholarship and geographies of sexualities, which focus on subjectivities, self-conceptualizations, identifications, strategies, experiences, and everyday lives.

\subsubsection{A Transnational Approach to Migration Studies}

One perspective that has been particularly foundational for the formulation of the queer perspective on migration has been critical transnationalism. Countering narratives of globalization organized around notions of unfettered flows of capital, goods, and services enabled by 'shrinking distances,' increasing speed, and decreasing costs of transportation and data flows, critical transnational scholarship seeks to examine the experiences and transcultural practices of people crossing borders. Yet it also engages with the conditions shaping migrant experiences (Glick Schiller, Basch, and Blanc-Szanton 1992). ${ }^{41}$ This dual objective has not only effectively upset enthusiastic notions of a de-borderized, de-territorialized and de-nationalized world but has also countered the common reduction of the migrant-laborer to a mere victim of a globalizing economy. The work of critical transnationalism scholars has moreover convincingly challenged larger transnationalism theory's perhaps most foundational assumption: that our networked present is to be juxtaposed in opposition to a more settled, simple, and bounded past (Featherstone 2007).

Studies employing a critical transnationalism perspective expose that the concepts of 'integration'/'assimilation' and 'segregation'/'multiculturalism' respectively provide apt models to explain the host society's expectations towards, and representations of, migrants, rather than models descriptive of migrants' understandings of themselves and their place in the world. By contrast, critical transnationalism studies portray migrants' self-understandings, which are often framed in terms of "split loyalties" (AbuLughod 1991), of cross-national and polycentric group memberships and citizenships, and multifarious cross-border connectivities. Particular attention is paid to the role of structures that enable the formation and maintenance of such transnational networks and ties, such as cellphones, the internet, telephone calling outlets, satellite dishes, 'ethnic' food stores, Western Union bureaus, and so on (Ley 2004:155, Richter 2006). Martin Manalansan succinctly summarizes the transnational perspective as follows:

No longer prone to 'permanent rupture' from the homeland or total subservience to the hegemonic practices of the adopted nations, these 'transmigrants' are living lives that

41 Some critical transnationalism scholars distinguish between critical transnationalism scholarship and transnationalism literature 'at large.' These scholars set out to write against what they see as 'at large'-transnationalism literature, which they portray as a distinguishable body of economic-, techno-, urban-, and Western-centric literature heralding borderless flows of goods, culture, capital, information, and bodies. It is particularly within such sweeping legitimizing moves opening many a text about transnationalism that I find the relationship between discourses around transnationalism and globalization respectively not sufficiently clarified. 
span and transgress borders and specific localities with new means of transportation and communication in what is now called a 'global ethnoscape.' (Manalansan 2000:184)

Although the transnationalist perspective frames migrants as agents in their own biographies and transgressors of material and symbolic borders, authors writing from this perspective do still address restrictive structural factors. Critical transnationalism theory therefore acknowledges not only that propinquity is not a necessity to the maintenance of meaningful social ties but also that this tying of ties is not unconditioned but rather highly structured and unevenly distributed depending on who does, or can do, the tying to whom, where, when, through what means, and to what end.

Contrary to what its name suggests, 'transnationalism' does not herald the end of the nation and its borders. Most transnationalism scholars agree that transnational formations not only depend on national identifications and systems of meaning but also are particularly productive of specific national imaginations and belongings (e.g. Jackson et al. 2004, Leitner and Ehrkamp 2006, Ley and Waters 2004, Mitchell 2004, Pratt and Yeoh 2003, Staeheli and Nagel 2006). As emerges from the interviews conducted in this study, the proliferating and persistent hegemonic discourses around nation and nationality supply a crucial terminology through which interviewees (have to) make sense of their Selves and their place in the world.

That being said, one critique of transnationalism scholarship has been particularly central to my understanding of the 'field' with which this study is engaged. In their collection of essays, Transnational Spaces, geographers Peter Jackson, Philip Crang, and Claire Dwyer conclude a review of recent work in the field that

studies of the economic, political and cultural dimensions of transnationalism have characteristically underplayed the transformation of space that is involved in the evolution of transnational social forms. Rather than taking space as a passive backdrop to transnational social relations, we argue that space is constitutive of transnationality in all its different forms. (Jackson et al. 2004:1)

Writing against notions of space-as-container, the authors call for work demonstrating that transnationalisms, in plural, vary over space and time. One of Jackson et al.'s claims stands out in particular: that "increasing numbers of people participate in transnational space, irrespective of their own migrant histories or 'ethnic' identities" (Jackson et al. 2004:2, emphasis added). The authors base their argument on Avtar Brah's concept of 'diaspora space,' which she sees as inhabited not only by diasporic subjects but also by those represented and perceived as non-diasporic:

The concept of diaspora space (as opposed to that of diaspora) includes the entanglement, the intertwining of the genealogies of dispersion with those of 'staying put.' The diaspora space is the site where the native is as much a diasporian as the diasporian is the native. (Brah 1996:209, quoted in Jackson et al. 2004:3)

This means that both the figure of the 'native,' 'local,' or 'indigenous' (in the case of this study 'Switzerland' or 'Swiss') and the figure of the 'migrant' (in this case 'Bosnian, 'German, 'Asian,' or 'Muslim,' for example) are constantly renegotiated through the convergence of embodied trajectories in space, whereas these spaces (and bodies) are always 
already transnational. To take the seemingly 'native' trajectories out of the equation would otherwise mean to fail to account for what makes identities, objects, and practices always both 'Bosnian' and 'Swiss,' for example. In other words, these transnational and intersectional configurations and meetings-up are productive of a third kind of space (Bhabha 1994, Soja 1996).

With Jackson et al. (and, again, Massey and Marston et al.), I therefore advocate shifting the focus from notions of already-cultured subjects towards an understanding of 'cultures' and 'cultural identities' - and indeed 'identities' in general - as ongoing processes of identification within a transnational space. This is, however, not to direct the focus away from migrants' lives, their self-conceptualizations, their sense of place in the world, their desires and nostalgias for a border-crossing multitude of places, their participations in or resistances against multiple projects of nation-building, or their everyday strategies to navigate a transnational life - indeed, much of this study is about this very issue. The aim is rather to "push the transnational gaze deeper into the 'stuff' of everyday life" (Mahler 1999:713, quoted in Pratt and Yeoh 2003:160), shifting the focus away from essentialized notions of migrant subjectivities towards an understanding of how both migrant and non-migrant subjectivities are forged through the confluence of trajectories in a necessarily transnational space that is inhabited by migrants as much as it is inhabited by non-migrants and things non-human. ${ }^{42}$

\subsubsection{Sexuality - Migration - Home, Revisited}

Queer diasporic subjects, particularly those from the Third World, who are confronted with multiple displacements, are faced with the monumental task of creating and refiguring home. (Manalansan 2003:13-14)

How queer migrant women negotiate home and belonging, both 'here' and 'there,' has emerged as a central question from working with queer migrant women's biographical accounts. The significance of home-making is also addressed by other queer migration scholars who have equally identified 'sexuality - migration - home' as a triad of concepts in need of analysis.

'Home' can be many things. It can refer, for instance, to specific scales such as one's family home, one's apartment, or one's home town or home country. It can carry the notion of abode, hearth, privacy, roots, or paradise. Home-making can designate a matrix of social relations and practices aimed at creating a sense of belonging, for instance, negotiations of membership in families, partnerships, or communities. Further, a sense

42 With such a view, we can also begin to track transnational things (see e.g. Cook 2004, Woodward et al. 2008). Moreover, this extended notion of transnationalism can serve to disrupt the Westcentrism inherent in the vast bulk of transnationalism literature (in which the present study is admittedly complicit), directing attention to migrations among or within 'developing' countries. As Audrey Kobayashi and Sarah de Leeuw note: "It makes a difference whether Otherness occurs at a distance from the metropolis within a colonial context, as shown in Said's original work; in place in colonial contexts, as has occurred in the subordination of most indigenous peoples; or through the creation of diasporic or transnational communities of difference, as represented by most of the large non-white migrant groups today" (Kobayashi and de Leeuw, 2010:130-131, emphasis original). 
of home is always also an intrinsically affective and sensual affair; it can be triggered through touch, sound, smell, taste, or images, which link remembered past places or imagined and desired spaces to present places. Finally (but not conclusively), whether 'here' or 'there,' homes are both the real and imagined locations where everyday lives are played out (Valentine 1995a, 2001:65ff).

As discussed above, early queer geographies engaged with two kinds of homes. The first was the family home left behind by sexual dissidents. The stories of queer people who left their heterosexual family home in order to live a liberated homosexual life in the city disrupt heteronormal conceptualizations of the home, which frame the space of the home as a place of regeneration and as a safe haven protected from the public eye. The queer geographical perspective on the home has shown that 'home' can have different meanings for people with dissident sexualities. For them, 'home' may be connected to surveillance, contestation, fear, and exclusion, for example.

The second kind of 'home' earlier queer geographical work addressed was the home queer people seek to forge as members of the 'queer family' in urban gay communities. This 'Great Gay Migration' narrative has rendered queer migration a curious kind of migration: For queer subjects there is "no locale from which to wander" since there is no homeland to validate a group identity (Warner 1993:xvii, quoted in Fortier 2001:408409) The homosexual subject's home is hence framed in terms of a destination rather than an origin; "instead of dispersing, we assemble" (Sinfield 2000:103, quoted in Fortier 2002:183).

As emerged from the empirical data generated in the context of this study, while for both internal and international queer migrants there often continues to be some truth in the 'move out to come out' narrative, the understanding of home in queer migration research has become more complex by engaging with the home-work of multiple marginalized queer subjects such as rural dwellers or international migrants. This work can be divided into two strands of thinking. The first considers queerness and queer migration in terms of borderline spaces and identities. Emphasizing the paradoxical and elusive aspects of queer migrant subject positions, this view situates queer migrant subjects' home in "placelessness" (Knopp 2004) or in liminal spaces such as a "third space," a "space between," or an "interstitial passage" (Bhabha 1994, quoted in Mai and King 2009:298). The second view on home in queer migration studies places more emphasis on articulations of processes of uprooting/re-grounding (Ahmed et al. 2003), and on more complex understandings of queer migration as entailing both estrangement from, and reproduction of, home (Ahmed 1999, quoted in Mai and King 2009:298, see also Ahmed et al. 2003, Fortier 2003, Kuntsman 2009). Through this perspective, homes, both 'here' and 'there,' are understood as being continually renegotiated and reconfigured. Here, home emerges as "a site of attachment which engages us in complex multidimensional relations, encompassing multiple returns to the past and renegotiations in the future" (Mai and King 2009:298). ${ }^{43}$ This home-making is driven by what Avtar Brah (1996) has termed 'homing desires,' which are "desires to feel at home achieved by physically or symbolically (re)constituting spaces which provide some kind of ontological security in the context of migration" (Fortier 2003:115). Hence, here, home does 
not necessarily have to be located in the family home or the country of origin. Rather 'homing desires' are distinct from the desire for a homeland, undermining the ideology of 'return' inscribed in hegemonic ideas about diaspora (Brah 1996:16). Nor is home necessarily a positively connoted space; instead, home-making is exposed as an often ambivalent and contradictory process. For instance, although queer people's parents often do not accept their children's homosexuality, the family home often still remains a home to the queer family member in many ways, as observed, for instance, in the continued sending of remittances (Cantú 2009). This study draws from and extends both these lines of thinking about the conceptual triad of 'sexuality - migration - home.'

\subsubsection{Identification: Intersectionality, Disidentification}

Questions of home and belonging are closely tied to processes of identification. Hence, this last sub-chapter reviews two theories about identity that have been advanced by queer migration scholarship, and which have inspired this study. The first is the concept of intersectionality, which is here extended by rethinking it from a spatial perspective. The second is the concept of disidentification formulated by José Esteban Muñoz (1999), which theorizes processes of identification in the context of the stratification, proliferation, and complication of subject positions.

As already touched on in Chapter 2 , the concept of intersectionality frames identities as a result of multiple processes of social differentiation based on, for instance, race, class, gender, or sexuality and specifically calls for an analysis of the interlacing and mutual constitution of these systems of oppression. Scholars of numerous disciplines and continents have worked with this concept as part of a framework to understand the ways people are assigned positions (and position themselves) in a world in which questions of identity, identification, and belonging have gained overarching significance. However, intersectionality theorists grapple with a number of dilemmas, which especially, but not conclusively, include the following:

First and most prominently, the term 'intersectionality' in itself precludes an unthinking of delimited social categorizations since it evokes the image of a crossroads of preestablished, bounded categories - as does alternative terminology encountered in intersectionality literature such as 'interlacing,' 'interlocking,' 'interdependent,' 'multiple,' and so on. In some ways, the inescapable terminology used in research applying an intersectionality perspective therefore paradoxically works against its own core argument, which is that gendered, classed, sexualized, racialized, ethnic, and so on, identities are mutually constitutive, with the formulation of one category necessarily depending on the simultaneous formulation of others. One example is the mutual constitution of race, gender, and sexuality. The figure of the Jezebel, for instance, is a stereotypical representation of Black women that originated under slavery and signified a sexually aggressive wet nurse. This depiction of Black enslaved women as having excessive sexual appetites served to legitimize white men's sexual exploitation of them as well as the suppression and appropriation of Black women's alleged heightened fertility (Collins 2000:82, quoted in Lugones 2007:204). Another set of stereotypes casts Asian women as either superfeminine (the "China Doll") or castrating (the "Dragon Lady") (Espiritu 1997:135, quoted in Lugones 2007:205; see also Haritaworn 2007). Anne McClintock de- 
scribes the colonial scene in general as a "porno tropic tradition," in which "women figured as the epitome of sexual aberration and excess." Against this backdrop, "[Western] sexual purity emerged as a controlling metaphor for racial, economic and political power" (McClintock 1995:22,47). Hence, there is no non-sexualized or non-gendered colonial Other; instead, the sexuality and gender of the Other is an integral part of her definition. At the same time, the colonial Other is constituted as that against which European sexuality and gender, and the colonial Self in general, becomes defined as 'normal.' As María Lugones writes, "it should be clear by now that the colonial, modern, gender system cannot exist without the coloniality of power, since the classification of the population in terms of race is a necessary condition of its possibility" (Lugones 2007:202) ${ }^{44}$ As the biographical narratives of queer migrant women generated in the context of this study testify to, these historical racialized, gendered, and sexualized figures and transformations continue to shape Western perceptions of non-Western cultures and people in many ways (see Chapters 5 to 10).

Hence the formulation of ethnicity and gender always already implies an actualization of sexuality, and vice versa. Intersectionality scholarship thus paradoxically attempts to theorize mutual constitution while at the same time failing to unimagine the boundedness of the various 'parts' feeding into these emerging multiple identities as already preexisting. As Jasbir K. Puar summarizes: "Intersectionality demands the knowing, naming, and thus stabilizing of identity across space and time, generating narratives of progress that deny the fictive and performative of identification" (Puar 2005:128, emphasis added).

Second - and this parallels the problems inherent in the scale literature as criticized by Marston et al. - the practice of organizing research around a very limited range of usual-suspect identity categories (race, ethnicity, class, gender, and sometimes sexuality, age, religion, or bodily ability) has become so common that these categories, like scales, begin to appear as conceptual givens, threatening to undermine their originally intended epistemological and heuristic status.

The third problem is methodological. As Leslie McCall remarks, "despite the emergence of intersectionality as a major paradigm of research in women's studies and elsewhere, there has been little discussion of how to study intersectionality; that is, of its methodology" (McCall 2005:1771; see also Büchler 2009a, Tuider 2011). This question is particularly relevant within the Germanophone debate where some of the most prominent intersectionality scholars, especially Gudrun-Axeli Knapp and Cornelia Klinger (Klinger 2003, Klinger and Knapp 2005, Knapp 2005a), have diagnosed an unhealthy predominance of 'micro studies' in intersectionality research. They argue that such 'micro' approaches can merely map effects of societal structures on individual lives, resources, and identity formation. Accordingly, these critics call for the formulation of a 'broader' social theory ("Gesellschaftstheorie") on the 'macro level' to develop an analytical

44 Lugones uses the term "gender systems" broadly, but especially in reference to heterosexuality or, as she calls it, "heterosexualism." Under this she subsumes for instance sexual acts and violence, the (depiction of the) anatomy of sexual(ized) body parts or notions of family organization, gender roles, and the division of labor. This corresponds to what I understand by 'sexuality' here. 
tool to address power structures working on the level of society 'at large' ("Herrschaftskritik"). These texts typically hierarchize categories, foregrounding the categories of race, class, and gender as 'core categories' (ibid). ${ }^{45}$ Contrasting this, other authors (more in tune, as it seems, with the more recent Anglophone debate) have emphasized the importance of analyzing the intimate mechanisms of the interlacing of social categorizations in case studies, using qualitative methodologies such as biographical interviews in particular (Lutz 2001, Lutz and Davis 2005).

Unfortunately, there is no solution to these dilemmas from within intersectional thinking. Moreover, these questions are intimately tied to scholars' and activists' efforts to usefully complicate what many continue to see as the most effective politics to achieving social justice, which is a politics based on essentialized identities. ${ }^{46}$ Notwithstanding these persistent dilemmas, there is no question that intersectionality theory has made our thinking about identity more sophisticated. The conception, design, and methodology of the present project, too, have been crucially shaped by the concept, especially in its early phases. I therefore want to frame my following deliberations, in which I put the concept of space as elaborated in Chapter 3.1, in conversation with the concept of intersectionality, as attempts to think beyond intersectionality that will certainly be in need of future elaboration and corrective.

Jasbir K. Puar argued in an interview with two colleagues of mine and myself that intersectionality, like hybridity or multiculturalism, needs to be thought of, and taught, as one of many conceptual tools that emerged in a very specific historical moment in U.S. feminist theorizing, and calls for abandoning the attempt to install the concept as an abstract theoretical frame capable of explaining all differences anywhere, anytime. She observes that in Anglophone scholarship (as in Germanophone literature), intersectionality is frequently used as a "buzzword," a "sound bite," a "shortcut to signal difference" casually invoking: "Well, everyone's got these different identities, and they play out differently in different space and time," rendering the concept "disvacuous, dehistoricized and untheorized" (Puar in Büchler et al. 2007:9). Puar problematizes a thus stripped intersectionality:

Maybe the main thing is that I am concerned about the ways in which intersectionality still freezes both space and time. The intersectionality of the identity is located in some kind of timeless and aspatial body. It's a way in which the identity can be multiple, and you've got your race-class-gender, and you add to that sexuality, nation, religion and so on. So you've got the components, but identity as a temporal and spatial process doesn't necessarily get addressed in addressing these components. Identification is a

45 In addition to my fundamental critique of such an approach as laid out below, I would like to note that the authors do not deliver evidence to support their claim that case studies were at the time predominant in Cermanophone intersectionality research. I am only aware of a relatively small number of Germanophone case studies explicitly applying an intersectional perspective at the time Klinger and Knapp write, although it is true that since then, the use of the concept has exploded in Cermanophone ethnographic migration research.

46 The political strategy, strategic essentialism, involves a conscious 'glossing over' of internal differences to represent one's group as bounded and unified in order to reach political goals forwarding social justice for (the actually internally much more differing) members of this group (Spivak 1993). 
process, it's a continuing modality of identification, it's not something that just freezes and then you can start talking about these various things. And I don't think that even sophisticated analyses of intersectionality have really been able to address that. (Puar in Büchler et al. 2007:9-10, emphasis original)

In an attempt to bypass these failures of intersectional thinking, Puar draws on Gilles Deleuze's concept of assemblage to theorize the production and mobilization of the terrorist body. She argues that while intersectionality still privileges the subject and subject formation, assemblage is "a way of thinking about bodies as opposed to subjects, [a]nd the matter of bodies as opposed to the consciousness of a subject identity," which usefully addresses that:

Identity is a kind of retrospective formation, it's always retroactively that you decide on an identity because you're constantly moving. [There] are different ways of disaggregating or rematerializing bodies that do not fit into these race-class-gender categories, and this is a whole other way of codifying the body. (Puar in Büchler et al. 2007:10)

Puar particularly explores the ways in which such new ways of thinking about the body may invigorate Queer Theory, which, while claiming to be 'anti-identity, has hardly ever been 'anti-subject,' but rather has been entrenched in subject formation (ibid:10).

In her paper "Queer Times, Queer Assemblages," Puar details her understanding of assemblage, which I render here to echo Marston et al.'s flat ontology as discussed above:

The Deleuzian assemblage, as a series of dispersed but mutually implicated networks, draws together enunciation and dissolution, causality and effect. As opposed to an intersectional model of identity, which presumes components - race, class, gender, sexuality, nation, age, religion - are separable analytics and can be thus disassembled, an assemblage is more attuned to interwoven forces that merge and dissipate time, space and body against linearity, coherency and permanency. [...] Displacing queerness as an identity or modality that is visibly, audibly, legibly, or tangibly evident, assemblages allow us to attune to intensities, emotions, energies, affectivities, textures as they inhabit events, spatiality, and corporealities. Intersectionality privileges naming, visuality, epistemology, representation, and meaning, while assemblage underscores feeling, tactility, ontology, affect, and information. (Puar 2005:127-128)

The notion of assemblage and its conceptualization of spaces and identities as mutually constitutive and ever-emerging hurls itself at the hegemony of the 'race-class-gender' triad in a debate in which other social categories are occasionally referred to as "playful differences" (Klinger 2003:26). ${ }^{47}$

47 Klinger draws on Donna Haraway to conceptualize physical work as the division line between "playful differences" and "world historic power systems." "World historic power systems" are class, race, gender; she does not understand sexuality to be organized around productive work (Klinger 2003:26, my translation). Moreover, Klinger assigns the three "world historic power systems" to scales: Klasse is assigned to the space "within the nation-state," Rasse to the space "without the nation-state" and Geschlecht to the space "within the nation-state, the society, the family" (ibid:31). This contradicts various strands of critical geographical scholarship, which has shown that all 
What this means in practice is that instead of naming the research subject in advance, identities should be allowed to emerge from research participants' accounts. Identities and spaces are not viewed as conceptual givens but are rather understood as processes of identification that are products of the coming-together of bodies, objects, rules, practices, and so on, in assemblage. This enables an examination of the conditions in which identity categories and places are mobilized during the telling of the story; further, it allows for a consideration of the bodies and relations making up the interview setting. Such a perspective therefore also creates knowledge about the performativity of spaces and identities - that is, the repetitive practices which produce and subvert dominant discourses around identities and spaces, and by which subjects are at the same time enabled and disciplined. Framing identity as an ongoing process of identification opens up conceptual space for this performance to deviate from the norm. ${ }^{48}$

In sum, such a view of identity formation accommodates that there is always more to an individual than the meeting-up of different bounded identities determined by a pre-selection of knowable trajectories of power. As Audre Lorde succinctly put it in her biomythography:

Being women together was not enough. We were different.

Being gay-girls together was not enough. We were different.

Being Black together was not enough. We were different.

Being Black women together was not enough. We were different.

Being Black dykes together was not enough. We were different.

(Lorde 1982)

"We are different," no matter how many components of identities are shared - and yet we strive for a 'we.' Concepts are therefore needed that allow for imagining alternative ways of (de)composing spaces and identities to escape the beaten path of some intersectional thinking.

José Esteban Muñoz equally proposes thinking of identity as processes of identification. While intersectionality provides a powerful tool to examine how certain subjects are assigned multiple marginalized positions in society, disidentification describes intersectional' subjects' strategies of identification. The concept of disidentification (which is based on an analysis of performances of queer artists of color in the U.S.) is "a mode of dealing with dominant ideology, one that neither opts to assimilate within such a structure nor strictly opposes it" (Muñoz 1999:11). It articulates the ambivalent, complex, and contradictory relationship between minority subjects and mainstream society, which

categories of social differentiation are intimately implicated in the production of, and produced through, all geographical scales.

48 As Sallie A. Marston points out, according to Gilles Deleuze, it is not exact repetitions that order the world but rather slightly varying ones, and these might ultimately make a significant difference (pers. comm.). Judith Butler's notion of slippage, especially as extended by geographers Cillian Rose and Nicky Gregson, equally speaks to this possibility of failures and subversions of the norm in the stylized, repetitive performances that (re)produce identities and spaces (Butler 1990, Gregson and Rose 2000). 
Muñoz situates beyond the binary assimilation/rejection. The term was forged by the French linguist Michel Pêcheux, who extrapolated the theory of disidentification from Louis Althusser's notion of subject formation as interpellation. ${ }^{49}$ Pêcheux formulates three modes in which a subject is produced by ideological practices: The first is 'identification,' in which the 'Good Subject' acts in accordance with the ideological system. The second is 'counteridentification' in which the 'Bad Subject' attempts to resist the assigned subject position by rebelling against the system but remains defined by the ideological structure. The third is 'disidentification,' which is neither a complete identification with, nor a rejection of, the assigned place, but rather works simultaneously on, with, and against dominant ideological structures (ibid:11).

"Disidentification," Muñoz writes, "is meant to be descriptive of the survival strategies the minority subject practices in order to negotiate a phobic majoritarian public sphere that continuously elides or punishes the existence of subjects who do not conform to the phantasm of normative citizenship" (ibid:4). Such strategies necessarily entail a destabilization of hegemonic meanings, working towards materializing and making visible alternative ways of being that can no longer be framed in terms of repeating, or failing to repeat, hegemonic positions alone. As Muñoz writes: "Disidentification is about recycling and rethinking encoded meaning. [...] Thus, disidentification is a step further than cracking open the code of the majority; it proceeds to use this code as raw material for representing a disempowered politics or positionality that has been rendered unthinkable by the dominant culture" (ibid:31).

Muñoz' concept is a useful complement to the extended notion of intersectionality discussed above as it builds on, and specifies, the notion of identities as always emerging and hence as open to difference, subversion, and slippage of identitarian norms. Although the concept emerged from an analysis of cultural productions in which performances are staged (such performative strategies are arguably often more conscious and more deliberately political than banal everyday life performances), the concept certainly resounds in participants' narratives in this research. An important caveat is that, as Muñoz himself also points out, disidentification is not always an adequate strategy for all minority subjects at all times. "At times, resistance needs to be pronounced and direct; on other occasions, queers of color [...] need to follow a conformist path if they hope to survive in a hostile public sphere. But for some, disidentification is a survival strategy that works within and outside the dominant public sphere simultaneously" (ibid:5). I have engaged with the concept of disidentification here precisely because it enables positive and productive formulations of otherwise 'impossible' subject positions, and places queer migrant subjects in a privileged position to both reflect ideological systems and to act as drivers of social change.

49 Drawing on Jacques Lacan's concept of the Mirror Stage, Louis Althusser (1971) theorized ideology as interpellation, i.e. as productive of subjects. He famously likened ideology to a policeman calling out "Hey, you there!" to a person in the street. In the moment the person turns around, she is transformed into a subject assuming her place in the Symbolic Order. Althusser calls this recognition a 'misrecognition' as it works retroactively: An individual is always already interpellated, even before she is born. 


\subsection{Who Are 'Queer Migrant Women'? Approaching the Research Subject}

After these theoretical deliberations, the question remains: Who are 'queer migrant women'? In other words: Who is the subject of this study? As Tom Boellstorff points out in the introductory remarks to a review on queer anthropologies, in which he addresses the problem of naming the subject in anthropologies of sexualities:

There is no more symptomatic, productive, and vexing starting point for this discussion than the impossibility of naming the very subject of study this review addresses. This impossibility constitutes not a problem to be solved but a kind of syntax error or event horizon reflecting the complexity of the subject under consideration. (Boellstorff 2007b:18)

Defining the subject of this research has been equally vexing, elusive and productive, as the remainder of this chapter attests. The following paragraphs are thereby as much a description of whom I have called to participate in this study as a portrait of those who came. I had established the search criteria for research participants at the outset of this project to include participants' sexuality (queer), migration 'generation' (first 'generation'), and their positionality in Switzerland as ethnicized/racialized 'Others.' The following sub-chapters present these criteria, but importantly also discuss how these criteria were transformed based on the progression of the search process, fieldwork, and continuous data analysis. This discussion does not include the factors according to which the sample was differentiated. These factors (which for instance included age, class, education, and status of residence) were, in contrast to the above three search criteria, consciously not fixed from the outset of the research but allowed to emerge from working on the data already generated. ${ }^{50}$ In other words, this final sub-chapter both serves to explain who this study originally sought to address while at the same time demonstrating the elusiveness of the attempt to name its subject.

\subsubsection{On Sexualities}

To start off, 'queer' was not how the research participants self-identify. Rather, I have used 'queer' as a conceptual umbrella that creates space for the twenty-eight conceptualizations of sexuality as represented by the twenty-eight queer migrant women who eventually took part in this study. ${ }^{51}$ This is not to atomize research participants, but quite to the contrary to acknowledge that "all identity categories are burdened by legacies that must be interrogated, do not map neatly across time and space, and become transformed through circulation within specific, unequally situated local, regional, national, and transnational circuits" (Luibhéid 2008a:170). Some, especially Anglophone, readers may be inclined to read such a usage of 'queer' as a neocolonialist move. Jasbir K. Puar, for instance, chose not to use 'queer' to describe non-heterosexual people in Trinidad "because queer does not yet circulate as a descriptor in Trinidad" (Puar

50 This procedure is based on the principles of Theoretical Sampling, see Chapter 4.

51 My thanks to Eithne Luibhéid for enabling this formulation (pers. comm.). Gayatri Gopinath uses a similar strategy in her book Queer Diasporas (Gopinath 2005). 
2001:1062). It is exactly for this reason that I do use the term here (though not in the process of looking for research participants, see below). Both in Switzerland and in most research participants' countries of origin, 'queer' was rarely used as a self-signifier when I was looking for study participants. ${ }^{52}$ Because of this, the term is, or was at the time, less fraught with the implications of the practices of an identity politics around 'queer,' as was happening in the U.S. or the U.K. where 'queer' as an identity category seems to have become another trope for exclusion (Shannahan 2010:674-675). Finally, 'queer' also serves to point to the (limits of the) theoretical framework upon which this project is based: As soon as I begin to think and write, I am confined to the concepts that are available at this point. In this sense I believe the concept of 'queer, in its intention as an open, anti-identitarian, and intrinsically intersectional concept, continues to be the best we have. ${ }^{53}$ 'Queer' as a methodology particularly also seemed supportive of "welcoming those who refuse assimilation," that is, of the unlearning, on my part, of my preconceived ideas about sexuality (Ahmed 2000:64, see Chapter 1).

More concretely, in this study the term 'queer' addressed woman-identified women who desire women and/or engage in sexual relationships with other women. First, these are women who explicitly identify with Western same-sex sexual identities such as lesbian or bisexual, or who identify with non-Western same-sex identities, like lesbi, tomboy, pengkid, mati, and so on. These identities are always also deeply gendered, that is, productive of distinct femininities and masculinities. For instance, Southeast Asian tomboys usually see themselves as "women in some fashion," but can understand themselves as women with men's souls, as was the case for one interviewee, or as social men in some respects, and may or may not like being described as 'lesbians' or even 'women' (Boellstorff 2007a:202). In other words, the biographies and self-conceptualizations in this study push against the limits of the concept of 'woman.' However, since eventually all participants explicitly self-identified as women (and not e.g. as men, or trans), I have decided to stick to the term 'woman' throughout this study. ${ }^{54}$ Second, 'queer' creates space for migrant women whose sexual practices do not align with their sexual identities (such as women who identify as heterosexual but engage in same-sex practices and/or relationships), as well as for women who frame their sexuality in terms of a practice rather than an identity.

52 At the outset of this research, in Switzerland 'queer' was mostly used to designate 'homosexual' cultural events or organizations, such as the Queersicht Festival in Bern or the Zurich Institut für Queer Studies. Since then, the term has become more frequently used in the sense of self-identification; it remains to be analyzed what people who identify as 'queer' understand by it (but see Naef 2020).

53 Note that some queer scholars have rightly warned that exactly this 'openness' of queerness can operate as the "modality through which 'freedom from norms' becomes a regulatory queer ideal that demarcates the ideal queer" (Puar 2007:22, quoted in Shannahan 2010:675). This concern is related to my critique of queerness-as-placelessness as discussed below (see Chapter 3.3.5).

54 It has been pointed out to me that I paradoxically insist on an emic term here ('woman') while I opt for the etic term 'queer' as the designator for all the sexualities scrutinized here. However, while 'woman' was the common explicit self-identification of all research participants, there was no such commonality in terms of sexual self-description. As laid out before, I was further operating with a notion of 'woman' that was kept fuzzy at its edges, including positionalities which would likely be termed 'trans' in the Western world (a term that was never used emically). 
While 'queer' is the term I have used in the theoretical framing and analyses, it was not the signifier I used in the process of looking for participants for this research. Seeing that the potential participants in this study were unlikely to identify as 'queer,' addressing potential interviewees was problematic and necessarily a bit of a circular argument: It was exactly the differences in how people conceptualize their sexual Selves that I was interested in, but at the same time I paradoxically had to hail participants using one terminology or the other in order to create a sample at all. As mentioned above, the potential participants were not necessarily going to identify as 'lesbian' or might indeed actively reject this descriptor; they might not frame their sexuality in terms of an identity at all; or they might have assumed other same-sex sexual subject positions in their countries of origin. With respect to the latter, since I had refrained from narrowing down my search to a specific country or region of origin (see below), I was barred from using emic terminologies in my call referring to sexual subject positions in potential participants' countries of origin.

Based on a number of explorative interviews I eventually settled on the term 'women-loving women'/'frauenliebende Frauen'/'femmes aimant les femmes' in the calls I issued. This seemed a term less ideologically burdened and less stigmatized than 'lesbian' or 'homosexual,' and more accessible than 'queer.' It moreover seemed more open to personal connotation, sounded positively valued, and could be read as inclusive of bisexual women; as one interlocutor said assertively: "C'est plus doux" - "It's softer." The fact that the term is unusual and hence causes a slight irritation at the same time meant it was usefully less fraught with meaning. I thought it an encouraging sign that some participants told me they had not been sure if they fit in this category. Overall, I believe this deliberately fuzzy wording has been pivotal in extending and disrupting the categories this research has sought to destabilize. This, I think, has outweighed the term's obvious drawbacks, especially its romanticization and potential invisibilization of female-to-female sexual desire. It seemed, however, that women who explicitly self-identified as 'lesbian' were not deterred from participation in the research by this alternative terminology, which was also true for interlocutors with a distinctly masculine gender positionality. However, even this term eventually did not solve the basic problem that to look for 'women-loving women' also meant to hail female women-loving subjects. ${ }^{55}$

Reflecting on the process of looking for research participants, the importance of the wording in the call has to be qualified for two reasons. First, the call triggered some responses that offered insights into perspectives that I had not expected to be able to include in this study. Women like Efra Mahmoud, Suki Schäuble, and Irena Pupovac (all names are anonymized) took part in the study despite the fact that they were very reluctant to identify as 'women-loving' - not to speak of 'lesbian' - and were generally times accompanied this recognition was indicative of the discomfort some participants felt in assuming this subject position. It is exactly these fissures and resistances that I attempted to move to the center of this study. 
extremely hesitant to speak about issues related to their sexual orientation. I had expected to be able to address this perspective only in retrospect, that is, through the narratives of women who see themselves as woman-loving today, speaking about former times in which they had not perceived themselves as such. I had, however, failed to account for the complexity and messiness of the 'field.' Efra Mahmoud, for example, seems to have felt obliged to respond since it was the lawyer who had generously supported her through her tedious immigration procedure that transmitted my call to her. Her motivation was further fueled by her identification as a social scientist and her consequent empathy for the methodological problems I was facing: "Ich kenne das weil ich habe schon mit Forschung und Sachen - ich kenne das einfach bis man jemand findet und die ganze Geschichte," - "I know this because I already have [done] research and things - I know how this is just until you find someone [to participate] and the whole story."

The second qualification for the wording of the call is that the call was only one of various ways in which participants were sought for this study (see Chapter 4). With the contacts established through my personal network I was often able to leave definitions much more open as the person establishing the link between myself and the participant helped to establish trust in me in advance. In addition, because these participants were doing a common friend or acquaintance a favor, they were more likely to participate even if they were skeptical about 'fitting' the categories I had provided. In other words, participants were obviously never only sexual but always complex subjects who, in the cases mentioned here, lent certain aspects of their Selves - loyalty to a friend, empathy for a fellow scientist, and so on - more significance than their (discomfort to speak about their) sexual practices or identity.

\subsubsection{On Generations}

In this study, 'migrant women' refers to women who have moved the focus of their everyday lives from another country to Switzerland, whether wholly or partially, permanently or intermittently, provisionally or definitely. Since I was especially interested in how participants' understandings of themselves and their place in the world had shifted through migration, this study primarily focused on women who had come to Switzerland as adults. However, since it proved very challenging to find and gain access to research participants, I eventually expanded my call to hail more generally women "with a migration background" - "mit Migrationshintergrund," some participants who had come to Switzerland as children or were born here. ${ }^{57}$ At the

French: "femmes immigrées." Note that the Cerman term 'mit Migrationshintergund' ('with a migration background') has since come under attack for drawing yet another line between 'us' and 'them' (LesMigraS 2012). Today, the terms 'with a migration foreground' ('mit Migrationsvordergrund') or 'with a migration biography' ('mit Migrationsbiographie') tend to be used emically instead.

57 In Germanophone Swiss migration research, the term 'zweite Migrationsgeneration'- 'second migration generation' - is often used to designate this latter subject position (but see Jain 2018). Who exactly is to be counted among the first and second migration generation respectively continues to be a contested issue within Swiss migration literature (Richter 2014). A popular yet blurred demarcation line is that only those who have taken the decision to migrate themselves are to be counted among 'first generation' immigrants. 
same time, attempting to draw a line between the first and the second 'migration generation' has proved largely futile as these categories overlap. This is for instance evident in the case of participants who migrated as teenagers, participants who have migrated back and forth between Switzerland and their home country over the course of several years, or participants who have one Swiss parent but did not grow up in Switzerland. Such biographical trajectories and constellations crucially shape the migration experience and play a central role in the place someone claims, can claim, and is assigned in Swiss mainstream society. For this reason, I have been transparent in the case analyses about the specific generational perspective of each participant, carving out the significance they ascribe to certain aspects of their 'migration generation' in their biographical narratives.

That said, both the sample and its analysis have clearly and deliberately remained biased towards participants who migrated to Switzerland as adults. In this sense, reflections about differences between participants of different migration generations have to be understood as casual observations or pointers to future research rather than a systematic comparative analysis. With respect to age at the time of migration, the sample was eventually structured as follows (again, these categories overlap): 21 participants migrated to Switzerland as adults (between the ages of 18 and 38, most in their early twenties); five as children (four at the age of ten, one at the age of six); three were Swissborn; and five had one Swiss or one German parent (two of whom were Swiss-born and three who had migrated to Switzerland as adults). Also, two participants were Swiss citizens from birth, one who had grown up abroad with one Swiss parent and one of the 'second generation' participants, who also had one Swiss parent and was born and raised in Switzerland. ${ }^{58}$

\subsubsection{On 'Culture'}

It is a truism to say that most qualitative migration studies examine diasporas that are predefined based on ethnicity, culture, religion (e.g. "Muslims in Berlin"), nationality (e.g. "Italians in Switzerland"), or region of origin (e.g. "South Americans in Germany"). Seeing the importance attributed to national, ethnic, and cultural identity in the making of modern Selves, such approaches are certainly justified to a certain extent. Unfortunately, these choices often fail to be problematized, with the national, ethnic, cultural, or religious identity, or the nation or region of origin studied being treated as self-explanatory, monolithic givens. As such, migration scholarship regularly falls into the trap of assuming scales such as the nation or the region as conceptual facts. As critical geographers like Sallie A. Marston and her colleagues have demonstrated (see Chapter 3.1.2), such a lack of reflection unusefully predetermines aspects of a research project rather than inviting reflection on the research design and sampling.

In this study, I eventually refrained from predefining the sample by defining a specific country or region of origin. This decision emerged from work on the project and is not only based in the difficulty experienced in finding research participants. First, given the lack of a visible identity politics among queer immigrant groups in Switzerland,

A more comprehensive overview of the research participants is given in Annex I. 
there was no 'natural' place to start the investigation or to perform participant observation. This meant that hailing, say, 'Kosovo-Albanian lesbians in Switzerland' would call into being an identity, a 'we,' that did not exist as such prior to the study. I therefore decided to conduct a broad initial search, thinking this would lead me to informal networks of queer migrant groups (however self-defined) by means of snowball sampling, which would then allow me to focus on a more 'culturally' or however specified group. This in turn would then enable me to provide a thick description of these communities and spaces. However, as discussed later, the participants in this study did not necessarily forge social networks along their national, ethnic, or cultural identity. If the snowball effect came into effect, it tended to point to other queer migrants who did not necessarily share the national, ethnic, or cultural background with the participant providing the contact. Cases in which participants were acquainted with queer compatriots were in fact very rare. ${ }^{59}$ This preliminary result was one reason why I decided not to narrow the focus to a specific nationality, ethnicity, or region of origin. These initial explorations also clarified that a restriction based on nationality, ethnicity, or region of origin would not generate a sufficient sample. ${ }^{60}$

A further reason against specifying the sample according to country or region of origin was the fact that at the outset of this study, queer immigrant activism in neighboring German-speaking countries was often organized around the collective term Migrantinnen (migrant women) rather than people of specific cultural backgrounds. This was - and in many cases still continues to be - evident in the names of these organizations, for instance ViennaMix and MiGaY in Vienna; Lesbische Migrantinnen and LesMAus in Linz; LesMigraS in Berlin; or QueerMigs in Zürich. These organizations worked and work towards connecting, empowering, and advising queer migrant people and queer people of color as they navigate the multiple mechanisms of discrimination in German-speaking countries. (LesMigraS, for instance, at the time focused on "Ressourcen, Bedürfnisse und Mehrfachdiskriminierungen von lesbischen und bisexuellen Frauen und Trans*Menschen (LBT*) of Color, LBT* mit Migrationshintergrund und Schwarzen $L B T^{* "}$ - "resources, needs, and multiple discriminations of lesbian and bisexual women and trans*people (LBT*) of Color, $\mathrm{LBT}^{* *}$ with a migration background, and Black LBT $^{* \prime}$ in Germany. $)^{61}$ In other words, when I was looking for study participants, queer migrant identity politics in German-speaking countries tended to focus on the shared queer/migrant/people of color identity and the attendant experiences of exclusion rather than on shared nationalities, ethnicities, or cultural backgrounds, which additionally seemed to justify my choice of keeping the sample inclusive.

The two small networks that I came across that were organized along the lines of national identity were not substantial enough to justify an exclusive focus on them (see Chapter 7).

60 On the other hand, sticking to a predefined specific nationality or ethnicity might have given the project another, no doubt also highly informative dynamic, and I hope other scholars will attempt this path. I have pursued it to some extent by distributing postcards that hailed 'women-loving women' of certain nationalities or ethnicities ('Tamil' and 'Albanian,' for instance) after realizing in the middle of my fieldwork that there was a dearth of representatives of these significant diasporas in my sample. Source: http://www.lesmigras.de/selbstverstaendnis.html, downloaded on August 26, 2014. 
Under the term 'migrant,' this research has thus subsumed immigrants who are perceived as Ausländerinnen (foreigners) in Switzerland and hence become defined as ethnicized/racialized Others based on social markers such as name, skin color, language, food, clothing, religion, body language, way of life, and so on. As described in the outline of Swiss immigration history in Chapter 2, the descriptor of Ausländerinnen, too, remains fuzzy: Who has been perceived as what kind of Ausländerin, to what extent, and during what period of time has been subject to significant shifts over the past decades. For instance, when one of the participants in this study came to Switzerland from Spain in the early 1980s, Southern European nationals were still met with a high degree of prejudice and mistrust. This has since shifted to Kosovo Albanians, people perceived as Muslims, and people of African descent, for instance. At the same time, the prejudices against earlier immigrant groups, especially Southern Europeans, have not simply vanished. As Fatima El-Tayeb points out, while "all parts of Europe are arguably invested in 'whiteness' as the norm against which ethnicization is read as a tool of differentiation between insiders and outsiders [in/from Europe]," it is "obvious nonetheless that both Eastern and Southern Europe's claim to this whiteness is more ambiguous than that of the Northwest of the continent" (El-Tayeb 2011:xiv). I agree with El-Tayeb that today Eastern Europeans "certainly constitute ethnicized labor" in Western Europe, but that Southern Europeans who migrated North in the context of the post-war guest worker binational contracts, too, "are still often suffering the effects of racialization" (ibid, see also Soom 2011). Following El-Tayeb's argument, I hence explicitly included Eastern and Southern Europeans in the group of "racialized minorities" in Europe (taking into consideration that the perceptions of and ascriptions to these different 'groups' of immigrants differ significantly).

In the end, study participants originated from six different countries in Latin America and the Caribbean; three Arab countries; seven Asian countries; three Southern European countries; and two former Yugoslavian countries (see Annex I). The cultural breadth of this sample has rendered it beyond the scope of this study to engage with the history of concepts of same-sex sexualities, socio-political positionings, and everyday realities of woman-loving women in these vastly different contexts (an endeavor that is moreover rendered impossible by the marked dearth of literature on female samesex desire, sexuality, and relationships in many of these contexts), but then again this has never been the goal of this study. Instead, the objective has been to understand the ways in which queer migrant women in Switzerland make sense of their former and current sexual Selves in retrospective, and particularly in light of their migration, as contemplated from their present standpoint. Explorations of how queer migrant women retrospectively perceive the places they grew up represent one specific perspective on these places, that is, the perspective of queer women (who may or may not have understood themselves as same-sex loving before emigration) who have moved to another country and are now looking back at their former Selves, lives, and home places and countries.

This study does not, in other words, treat participants as representatives of their nation, ethnicity, or culture - this would mean to gloss over the differences within, say, an 'ethnicity' as formed by gender, sexuality, class, language, and other aspects of the social (see, for example, Weston 1997 [1991]:12). It is also decidedly not about what it 
'is like' to live as a homosexual in Bosnia, Egypt, or Peru, but instead about what it is like to live in Switzerland as a queer migrant woman who emigrated from one of these places. The focus is on the effects of research participants' shared experience of migration, (sometimes) of historical European colonization, and of multiple displacements based on their gender, non-conforming sexuality, and positionality as Ausländerinnen in Switzerland. These shared experiences and other linkages, such as for instance a shared religion, also open up possibilities for transnational connectivities and resistances that exceed ethnic and national borders; these are particularly in focus here as well.

\subsubsection{On Immigration Status}

Besides 'regular' immigrants, in this study the term 'migrant' has also addressed Sans Papiers - undocumented immigrants - (who were eventually not represented in the sample), asylum seekers, and naturalized immigrants. The latter were considered because they remain marked as Ausländerinnen in their everyday lives even after they become Swiss citizens. As one informant phrased it: "Here, I will always be a foreigner." Asylum seekers and Sans Papiers have been included because, while most migration scholarship continues to frame 'forced' and 'voluntary' migration as entirely different spheres of experience by radically separating 'trafficked' people and refugees from 'regular' immigrants, I argue with Eithne Luibheid that this distinction "urgently needs to be rethought to account for how most migrations in fact straddle choice and coercion" (Luibhéid 2008a:178 and 2008b). Luibhéid further notes:

Such distinctions are less reflections of empirically verifiable differences among queer migrants, who often shift from one category to another, than techniques of nationstate power that remain centrally implicated in neocolonial hierarchies and that classify migrants in order to delimit the rights that they will have or be denied, and the forms of surveillance, discipline, normalization, and exploitation to which they will be subjected. (Luibhéid 2008a:186n)

The spatialities of migration further destabilize the logic of such a separation. Just like other migrants, asylum seekers and Sans Papiers, too, have traveled from one place to another, and they, too, have an everyday life in Switzerland, albeit a specifically structured one. Their lives rather center on waiting for refugee status, sometimes for several years, and on the fear of becoming exposed as undocumented or expelled from the country. Since it was these everyday lives and spaces in particular that were under scrutiny here, as well as how participants' perceptions of their sexual Selves shifted through these experiences, an a priori exclusion of asylum seekers and Sans Papiers did not seem justified. 


\subsubsection{On Language}

The call for research participants was provided in German, French, and English (and later also Albanian). Eventually, all interviews were held in German, Swiss German, French, and English. In many cases, research participants did not speak their mother tongues in the interviews (and neither did I, my mother tongue being Swiss German), which emphasized the already sensitive issue of researchers doing research in, and translating data from, a 'foreign' language (Müller 2007, Smith 1996). ${ }^{62}$ In the call, I offered the possibility of bringing one's own interpreter, but nobody made use of this option. I ascribe this to two facts: First, the snowball system worked rather poorly in this project. I had hoped that people who had participated in the research or had seen the flyer would refer the information to friends, family members, or community members who did not speak any of the languages used in the call, but this only happened in one instance (which eventually did not result in an interview). Second, many research participants were more than capable of speaking in one of the offered languages. This was partly also owed to the fact that most participants were well-educated. Usually, everyday use of one of the interview languages was normal, and it was sometimes also the language used by binational couples to communicate. This is not to deny but perhaps to qualify the often-lamented loss of nuance and detail when speaking in a foreign language.

A few cautionary notes on the definition of the subject(s) of this study to conclude. Like any other, this definition of the research subject - 'queer migrant women' - includes certain subjects and subject positions while excluding others. Marking mati, lesbian, tomboy, supi, bisexual, and other sexual identities as 'queer' may be a noble gesture to demonstrate open-mindedness and resistance to closure. However, it also glosses over the fact that we as researchers simply cannot include the things in our study concepts that we cannot think because we don't know them. With the theoretical tools we have available in queer postcolonial theory to date, we can always only think as far as we can name specific sexualities, and maybe we can analyze some interactions between them, or suspect the limitations of their conceptualization. However, even today, we cannot know what next letter will be attached to the acronym LGBTIQ ${ }^{+}$, or what alternative conceptualizations of sexuality may further transform queer theory in the future.

At the same time, an open mind - as the concept of 'queer' requests - may help us to look actively for ways in which analyses conducted in the 'dirt and rock' of everyday lives and spaces may change our thinking about sexuality. Indeed, at the outset of this

62 However, Fiona Smith warns against binarizing doing research in the 'home' language versus doing research in a 'foreign' language, seeing that even within one linguistic community language is never transparent or directly representative of a reality outside of it. Smith therefore advocates a productive approach to doing research in foreign languages, arguing that reflections on the translation of key terms can open spaces in between languages that in turn can create new spaces of insight which are not inhabitable when working from within the 'home' language - and which simultaneously effectively de-center the assumed transparency of the 'home' language, too (Smith 1996:162-163). 
research, I could certainly not have come up with the definition of the research subject I have just written; it was not forged at the outset, but rather at the close of this project, and thus was a result rather than an axiom, betraying the text's seemingly linear logic. Time and again, what I thought were the subjects of my research and the field of research escaped my grasp, just as I already feel my latest attempt slip through my fingers now. At this point, therefore, I can do no better than to tell some of the tales from the field in which all of this slipping occurred, emphasize the provisional nature of the above outline, and invite suggestions for its enhancement, extension, or productive dissolution. 
